\title{
Carotenoids: Therapeutic Strategy in the Battle against Viral Emerging Diseases, COVID-19: An Overview
}

\author{
Ayman Khalil', Diana Tazeddinova', Khaled Aljoumaa', Zhumayeva Araigul Kazhmukhanbetkyzy², \\ Ayan Orazov' ${ }^{2}$, and Abduvali Djabarovich Toshev ${ }^{1}$ \\ ${ }^{1}$ Department of Food technology, South Ural State University, Chelyabinsk 454080, Russian Federation \\ ${ }^{2}$ Higher School of Technologies of Food and Processing Productions, Zhangir Khan University, Uralsk 090009, The Republic of Kazakhstan
}

\begin{abstract}
Carotenoids, a group of phytochemicals, are naturally found in the Plant kingdom, particularly in fruits, vegetables, and algae. There are more than 600 types of carotenoids, some of which are thought to prevent disease, mainly through their antioxidant properties. Carotenoids exhibit several biological and pharmaceutical benefits, such as anti-inflammatory, anti-cancer, and immunity booster properties, particularly as some carotenoids can be converted into vitamin A in the body. However, humans cannot synthesize carotenoids and need to obtain them from their diets or via supplementation. The emerging zoonotic virus severe acute respiratory syndrome coronavirus 2 , which causes coronavirus disease 2019 (COVID-19), originated in bats, and was transmitted to humans. COVID-19 continues to cause devastating international health problems worldwide. Therefore, natural preventive therapeutic strategies from bioactive compounds, such as carotenoids, should be appraised for strengthening physiological functions against emerging viruses. This review summarizes the most important carotenoids for human health and enhancing immunity, and their potential role in COVID-19 and its related symptoms. In conclusion, promising roles of carotenoids as treatments against emerging disease and related symptoms are highlighted, most of which have been heavily premeditated in studies conducted on several viral infections, including COVID-19. Further in vitro and in vivo research is required before carotenoids can be considered as potent drugs against such emerging diseases.
\end{abstract}

Keywords: anti-inflammatory, antioxidants, antiviral agents, carotenoids, COVID-19

\section{INTRODUCTION}

The world continues to face a pandemic crisis caused by the newly discovered severe acute respiratory syndrome coronavirus 2 (SARS-CoV-2), which causes coronavirus disease 2019 (COVID-19). SARS-CoV-2 is a highly pathogenic infectious virus that has infected over 178 million and lead to the death of $\sim 4$ million people worldwide as of June 2021 (Dong et al., 2020). SARS-CoV-2 is a singlestranded RNA virus that belongs to the genus Betacoronavirus, one of four genera of Coronaviridae. At the nucleic acid level, SARS-CoV-2 shows $78 \%$ similarity with SARS$\mathrm{CoV}$ and $50 \%$ with the Middle East respiratory syndrome coronavirus (MERS-CoV). SARS-CoV-2 is transmitted via aerosolized droplets via direct contact and oral-fecal, and generally has an incubation period of 5 to 14 days, reaching 24 days in certain cases. At the onset COVID-19, the main symptoms are fever, cough, fatigue, and muscle pain and, in severe cases, many patients show signs of dyspnea, acute respiratory distress syndrome (ARDS), cardiac injury, multi-organ failure, and shock (Zhong et al., 2020). The risk of serious COVID-19 infection increases with age, male gender, and underlying health problems, such as cardiovascular diseases, obesity, diabetes, chronic obstructive pulmonary disease (COPD), and asthma (Goyal et al., 2020). Accumulated data suggest that COVID-19 is characterized by a hyperinflammatory state in which pro-inflammatory cytokines that underlie the pathology of COVID-19 infection, such as tumor necrosis factor- $\alpha$ (TNF- $\alpha$ ), interleukin (IL)-6, IL-2, IL-17, granulocyte-macrophage colony-stimulating factor, monocyte chemoattractant protein 1 (MCP-1), macrophage inflammatory protein $1-\alpha($ MIP-1 $\alpha)$, C-reactive proteins (CRP), and interferon (IFN) $-\gamma$ inducible protein 10 (IP10), are prominent (Xu et al., 2020). Patients with COVID-19 show immune system perturbation with pro- 
found alterations of various components, such as decreases in peripheral $\mathrm{T}$ lymphocytes, natural killer (NK) cells and $\mathrm{CD} 8^{+} \mathrm{T}$ cells, loss of major histocompatibility class (MHC) class II molecules, and increases in chemokine production from monocytes (Huang et al., 2020a). Since no active medication is yet available and limited amounts of vaccines are used worldwide, strengthening immune systems thorough diet may be central in the combat against the virus and its related symptoms. Indeed, phytochemicals and selected foods, such as garlic, ginger, basil, drumstick, and liquorice/licorice, may inhibit several viruses including SAR-CoV by directly inhibiting either viral entry or replication, and by immunomodulation (Anand et al., 2021; Fasogbon et al., 2021). Furthermore, phytochemical-containing foods, such as cashew nuts and ginger, have been described to exhibit many health benefits for inflammatory processes and oxidative stress, which are the key factors in developing several chronic diseases such as diabetes mellitus and metabolic syndromes (Darvish Damavandi et al., 2019; Morvaridzadeh et al., 2020). In this regard, natural phytochemicals compounds such as carotenoids and polyphenols appear to have a role in this viral battle due to their acknowledged biological and pharmaceuticals effects in preventing several human diseases and maintaining good health. Some primarily contribute to vitamin A dietary, which has a potent role in COVID-19 treatment ( $\mathrm{Li}$ et al., 2020). High plasma and serum concentrations of carotenoids have been associated with a lower incidence of acute respiratory infections and immune response improvement in elderly people, resulting in a decreased risk of infectious diseases and improved pulmonary function (van der Horst-Graat et al., 2004; Semba et al., 2012). Herold et al. (2020) showed that CRP and IL-6 levels are elevated (IL-6: $>35 \mathrm{pg} / \mathrm{mL}$ at presentation and maximal value $>80 \mathrm{pg} / \mathrm{mL}$; CRP: $>32.5 \mathrm{mg} / \mathrm{L}$ at presentation and maximal value $>97 \mathrm{mg} / \mathrm{L}$ ) in COVID-19 patients, which is associated with risk of respiratory failure and a need for mechanical ventilation. Thus, IL-6 or CRP could be used to guide treatment acceleration in patients with COVID-19-related hyper-inflammatory syndrome. An inverse correlation between CRP, a marker of inflammation, and $\beta$-carotene have been reported in infants with acute infections. In addition, the association of lower CRP with higher carotenoid intake likely reflects carotenoid antioxidant and immunomodulatory properties in preterm infants (Cser et al., 2004; Rubin et al., 2012). According to the World Health Organization, maintaining a strong immune system with a nutritious diet rich in fruit and vegetables, and low in sugar and calories is important against COVID-19. Thus, diets containing carotenoids and polyphenols may be important for combating the emergence of COVID-19 and its related symptoms. This review summarizes and highlights the available up-to- date facts related to the potential role of the major carotenoids studied from natural sources in human immunity boosting, via their beneficial properties in the combat against COVID-19 and related symptoms. In addition, this review aimed to gather the literature on each carotenoid compound, to be used as a potential tool to further the antiviral pharmaceutical industry.

\section{RESEARCH STRATEGY}

The medical websites PubMed and Medline, and Science direct and Cochrane Library were searched for the carotenoids included in this review and were archived by the number of studies found on these sites. The initial electronic database yielded approximately 2,070 records. For each individual carotenoid compound, a detailed search was conducted with the following keywords: inflammation, immunity, immune, asthma, influenza, common cold, flu, lung, lung disease, pulmonary, fibrosis, ARDS, COPD, viral, anti-viral, virus, SARS, MERS, and COVID19, for each section of this review was followed. After evaluation of the titles and abstracts, and removal of duplicates, the full texts of 477 studies were examined and reviewed by the authors. Finally, $\sim 200$ articles containing outcomes on human health, published until March 2021, were included in this review. This included in vitro and in vivo to epidemiological studies. The most relevant papers, which elucidate the foremost role of each studied carotenoids as anti-inflammatory, immunity supporting, and anti-viral agents, were discussed and papers showing similar results were gathered or excluded from the reference list. Our strategy was based mainly on the beneficial role of carotenoids from natural sources that make up the human diet, and the relevant molecular pathways, particularly those involved in the combat against emerging diseases, such as COVID-19 and related symptoms.

\section{CAROTENOIDS: STRUCTURE, CLASSIFICATION, SOURCES, AND BIOLOGICAL ACTIVITIES}

Carotenoids, a large group of organic compounds that are biosynthesized by plants, bacteria, and fungi but not humans (Ruiz-Sola and Rodríguez-Concepción, 2012; Kiokias et al., 2016; Maoka, 2020), have a common backbone structure called polyene chain, which is a system of conjugated double bonds and two end groups (Maoka, 2020) (Fig. 1).

In general, carotenoids are tetraterpenoids containing eight isoprenoid building blocks (e.g., isoprene in Fig. 2). Four isoprenoids are present in the polyene backbone and four are present in the two end groups (Kiokias et al., 2016; Meléndez-Martínez et al., 2019). 


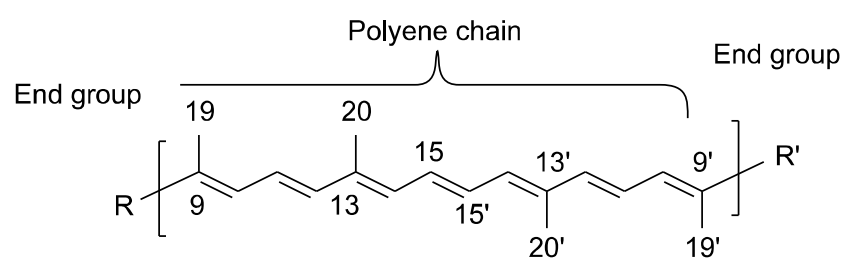

Fig. 1. Shared backbone structure of the majority of carotenoids.

Carotenoids can be grouped in different classes chemically or by activity, and usually contain 40 atoms of carbon (Table 1). Carotenoids may be described as carotenes that have cyclized or acyclized hydrocarbon end groups, or as xanthophyll, which has oxygenated end groups (hydroxyl, epoxy, carbonyl, etc.). Furthermore, many carotenoid groups contain provitamin A and can be enzymatically converted in the intestinal mucosa to yield retinol (vitamin A) (Sayahi and Shirali, 2017).

Carotenoids (Table 1) have a wide variety of health benefits due to their protective and medical properties, ability to strengthen the immune system, and their antioxidant, anticancer, anti-inflammatory, antidiabetic and antiobesity/hypolipidemic activities (Krinsky and Johnson, 2005; Rao and Rao, 2007; Burrows et al., 2015).

\section{CAROTENOIDS ALLEVIATE INFLAMMATORY RESPONSES THAT LEAD TO ACUTE LUNG INJURY DURING COVID-19 INFECTION}

Inflammation is a preserved biological procedure characterized by activation of immune and non-immune cells that protect the host from invading pathogens (bacteria, viruses, and toxins) that may cause organ injury by eliminating, and promote tissue repair and recovery. Inflammation is mainly divided into two phases: an acute inflammatory response (typically occurring at the time of infection) and a systematic chronic inflammatory response (arising over the time of infection, and causing tissue and organ damage). Consequently, inflammation increases the risk of developing non-communicable diseases over time. The acute inflammatory response is typically characterized by temporally controlled up-regulation of inflammatory activity against pathogens. Switching the inflammatory response from short- to long-term inverses the acute inflammatory response into a chronic inflammatory response, which interrupts immune tolerance and leads to major modifications in all organs and tissues. These alterations increase the risk of impaired immune function, leading to infection vulnerability, and a poor vaccine response (Furman et al., 2019). Subsequently, inflammation is a key factor in the pathogenesis of many conditions, including chronic non-communicable disease (such as neurodegenerative diseases, arthritis,

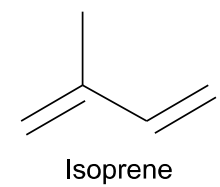

Fig. 2. Isoprene containing five carbon atoms is an example of an isoprenoid.

and diabetes mellitus) and infectious communicable diseases (e.g., the emerging infectious disease COVID-19). There is a strong correlation between inflammatory cascade severity, pathological progression, and organ damages in patients with COVID-19 (Huang et al., 2020b). Cytokine storms are a manifestation in the host immune response, characterized by overproduction of pro-inflammatory cytokines and chemokines including IFN- $\alpha$, IFN- $\gamma$, IL-1 $\beta$, IL-6, IL-12, IL-18, IL-33, TNF- $\alpha$, chemokine (CX-C motif) ligand (CXCL) 10, CXCL8, CXCL9, chemokine ligand (CCL) 2, CCL3, and CCL5 (Coperchini et al., 2020). This results in a reduction in the upsurge of the inflammatory storm during SARS-CoV-2 infection making it a major target for developing future drugs. Therefore, a favorable anti-inflammatory candidate targeting diverse mechanisms related to the cytokine storm should be taken into consideration. IL-6 plays a major role in inflammatory responses and is significantly augmented in COVID-19 patients, and could be considered a target for the treatment of COVID-19. In general, antagonizing inflammatory ILs, such as IL- 6 , and IL- $1 \alpha$, IFN- $\gamma$, TNF- $\alpha$ receptors, toll-like receptors (TLRs), and Janus kinasesignal transducers and activators of transcription-3 (JAK/ STAT) and nuclear factor- $\mathrm{\kappa B}$ (NF- $\mathrm{\kappa B}$ ) pathways could be of potential importance for reducing SARS-CoV-2 complications and suppressing COVID-19 (Coperchini et al., 2020; Yarmohammadi et al., 2021).

Lung tissue with the epithelial cells of the bronchial and alveolar are constantly exposed to air irritants and pathogens and produce a number of inflammatory mediators in response to injury. These tissues produce an immune response against the progress of the pathogen that involves several cell types critical for viral clearance and establishing antiviral immune memory. During infection with extremely pathogenic viruses, such as SARS-CoV-2 or influenza viruses (i.e., certain $\mathrm{H} 1 \mathrm{~N} 1$ and $\mathrm{H} 5 \mathrm{~N} 1$ influenza virus strains), failure to promptly clear these infections can lead to excessive uncontrolled inflammation, initiating lung tissue damage. However, vascular angiogenesis distinguishes the lung pathobiology of COVID19 from that of equally severe influenza viral infections (Ackermann et al., 2020; Alon et al., 2021). ARDS is characterized by acute lung injury (ALI) and increasedpermeability, lung edema and severe hypoxemia due to injury to the alveolar capillary barrier in lung tissues. ARDS is common cause of hospital admissions and death 


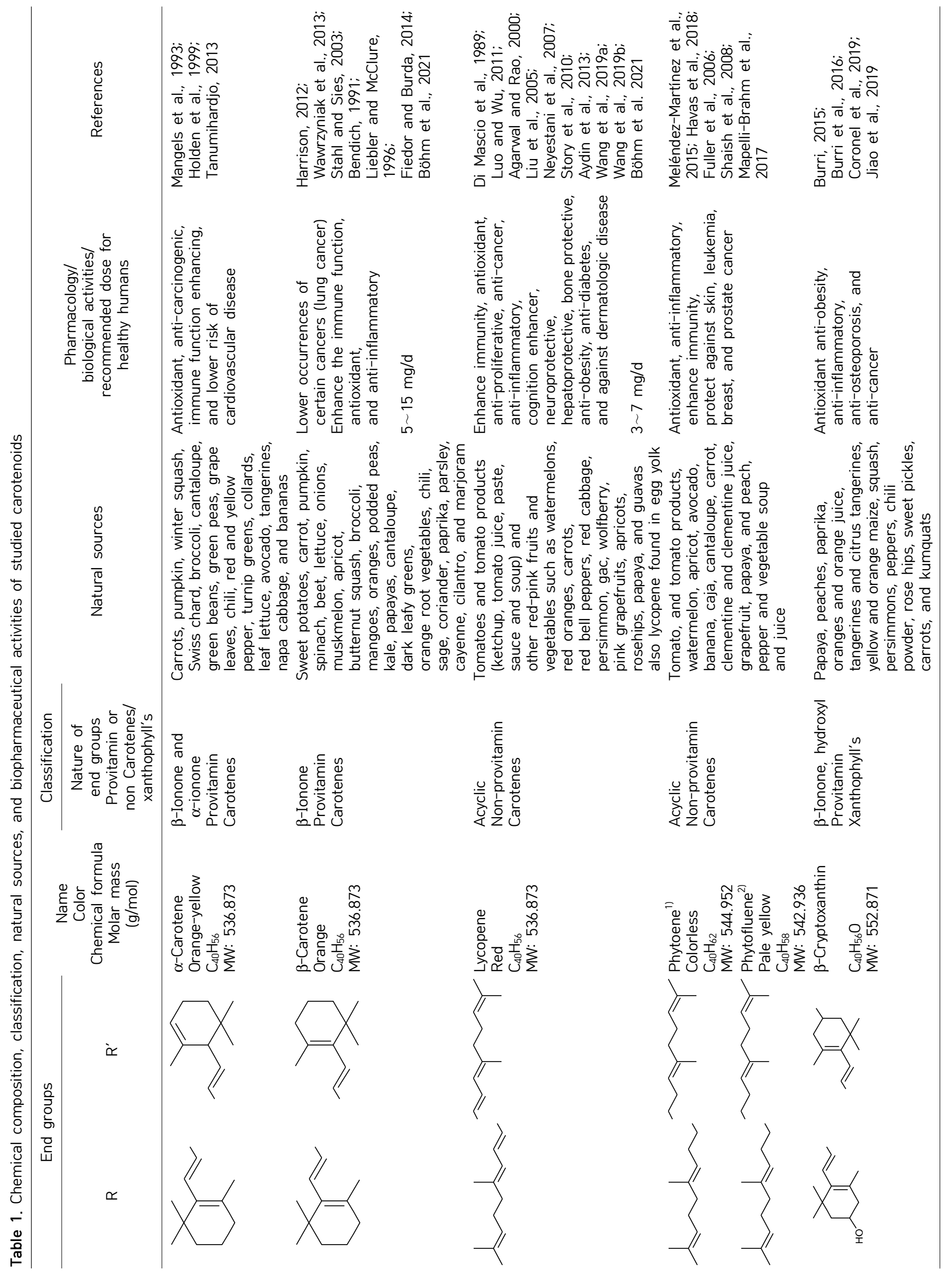




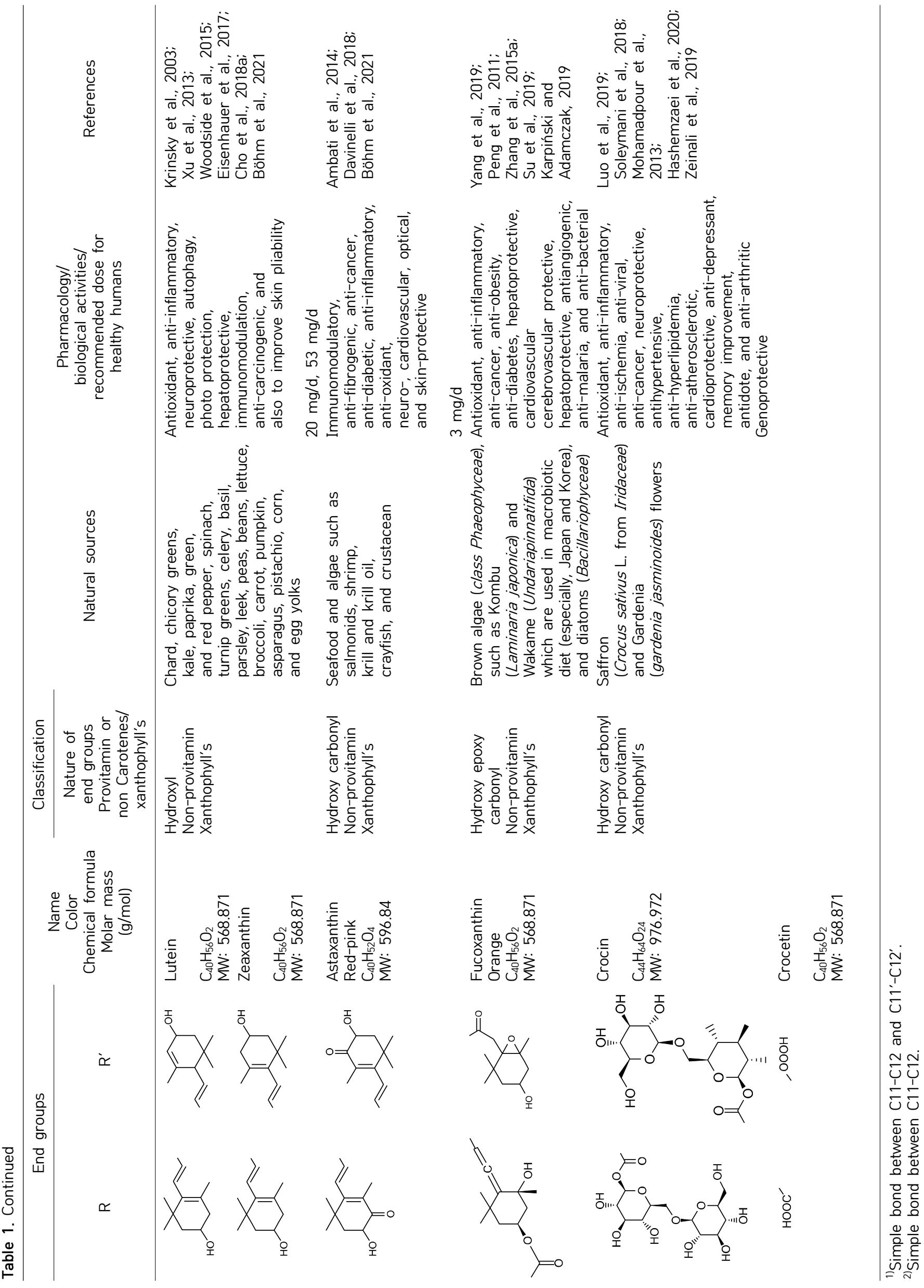


in patients with SARS-CoV-2 infection (Ware, 2020). ARDS is accompanied by deadly cytokine release (cytokine storm), in which IL-6 and neutrophils play a critical role in the development cytokines leading to hyperinflammation, resulting in ALI and, in some cases, irreversible lung tissue degradation (Alharthy et al., 2020; Korkmaz et al., 2020). Indeed, the cytokine storm that occurs during COVID-19 infection is characterized by an increase in intra-alveolar fibrin that stimulates production of both profibrotic growth factors and profibrotic cytokine transcripts, such as transforming growth factor- $\beta$ (TGF- $\beta$ ), connective tissue growth factor (cellular communication network factor 2), and platelet-derived growth factor. In addition, decreases in lung surfactant proteins leading to alveoli failure and altering lung compliance may provoke an ultimate environment for fibroblast adherence and growth, resulting in collagen deposition and development of lung fibrosis, which may eventually induce lung cancer (Fernandez and Eickelberg, 2012; Gallelli et al., 2020). There is increasing evidence that COPD prevalence and smoking may be associated with substantial severity and mortality rates from COVID-19 compared with those who are former smokers or those who never smoked (Alqahtani et al., 2020). This could be related to poor underlying lung reserves or increased expression of angiotensinconverting enzyme 2 receptors in small airways (Leung et al., 2020).

In this context, we reported the most important and relevant studies on the role of each carotenoid in inflammatory processes, chiefly inflammatory responses resulting from viral and airway infection.

\section{$\beta$-Carotene}

After absorption, $\beta$-carotene can be enzymatically converted into vitamin A by oxidative cleavage of provitamin $A$ via the intestinal enzyme $\beta$-carotene 15-15'-oxygenase (Harrison, 2012). Epidemiological studies demonstrated that high serum $\beta$-carotene levels are associated with lower occurrences of certain cancers, especially lung cancer, which might be due to the fact that $\beta$-carotene enhances immune function or through the antioxidant capacity of $\beta$-carotene (Bendich, 1991; Wawrzyniak et al., 2013). Indeed, $\beta$-carotene has strong antioxidant properties. $\beta$-Carotene scavenges free radicals and other oxidants involved in the pathogenesis of several chronic diseases processes, mainly reactive oxygen species (ROS) types, such as the superoxide anion radical $\left(\mathrm{O} 2^{\cdot-}\right)$, the hydroxyl radical $\left(\mathrm{HO}^{*}\right)$, hydrogen peroxide $\left(\mathrm{H}_{2} \mathrm{O}_{2}\right)$, and singlet oxygen $\left({ }^{1} \mathrm{O}_{2}\right)$ (Liebler and McClure, 1996; Fiedor and Burda, 2014). The strong antioxidant activity of $\beta$ carotene attributes to its anti-inflammatory propriety by preventing the oxidative inflammatory disorder, which is associated with tissue damage (Stahl and Sies, 2003). $\beta$ Carotene suppresses ROS-mediated inflammatory signal- ing pathways, such as mitogen-activated protein kinases (MAPKs), redox-sensitive transcription factors [such as NF- $\mathrm{KB}$ and activator protein 1 (AP-1)] and reduces proinflammatory cytokines, such as IL-8, inducible nitric oxide (NO) synthase (iNOS), and cyclooxygenase-2 (COX2) in human gastric tissues infected by Helicobacter pylori (Kang and Kim, 2017). Moreover, $\beta$-carotene inhibits expression of pro-inflammatory mediators, such as NO, prostaglandin E2 (PGE2), inducible iNOS, COX-2, TNF$\alpha$, and IL-1 $\beta$, by functioning as an inhibitor of NF- $\mathrm{KB}$ activation (Bai et al., 2005).

Synergistic effects have been described for bioactive lipid compounds from three algal red seaweeds (Porphyra dioica, Palmaria palmata, and Chondrus crispus) and one microalga (Pavlova lutheri). These compounds contain 34 $42 \%$ polyunsaturated fatty acids ( $\mathrm{n}-3)$ and $5 \sim 7 \%$ pigments, including chlorophyll A, $\beta$-carotene, and fucoxanthin, and effectively inhibit pro-inflammatory signaling pathways mediated by TLRs (e.g., TLR1, TLR2, TLR4, and TLR8), chemokines (e.g., IL-6 and IL-8), and NF- $\mathrm{kB}$ signaling molecules in lipopolysaccharide (LPS)-stimulated human THP-1 macrophages (Robertson et al., 2015). An earlier study demonstrated that $\beta$-carotene decreases phytohaemagglutinin (PHA)-stimulated proliferation of human peripheral blood mononuclear 6 times more than theophylline and sodium cromalyne. The study suggested use of $\beta$-carotene as an anti-inflammatory agent for bronchial asthma in clinical practice. Similarly, another study conducted on mice suggested that $\beta$-carotene is a promising drug for preventing and treating influenza as it decreases symptoms (Sukhinin et al., 1999, Landells et al., 2000).

$\beta$-Carotene, quercetin, and luteolin are the major compounds extracted from Qi-Wei-Du-Qi-Wan (QWDQW), a Chinese traditional medicine that is used to treat chest tightness, coughs, shortness of breath, night sweats, and asthma. QWDQW reduces overproduction of inflammatory mediators, such as IL-12, IFN- $\gamma$, IL-13, IL-4, regulated upon activation, normal $\mathrm{T}$ cell expressed and secreted (RANTES), eotaxin, and MCP-1, in the lungs of chronic asthmatic mice. In addition, QWDQW inhibits mast cell degranulation in RBL-2H3 cells and acts as an anti-asthmatic during treatment with each extract compounds (Lin et al., 2020).

Accelerated declines in lung function are observed over 8 years in heavy smokers who have low levels of antioxidants, which increases the risk of developing COPD. $\beta$ Carotene and vitamin E may have protection effects against this decline in lung function by reducing oxidative stress and excessive airway smooth muscle contractility and/or proliferation by neutralizing $\mathrm{O} 2^{\cdot-}$ associated with COPD pathogenesis. Additionally, $\beta$-carotene, alongside other carotenoids is associated with improved pulmonary function in patients with COPD (average total carotenoid 
intake: $9 \pm 7 \mathrm{mg} / \mathrm{d}$ ) (Guénégou et al., 2006; Jun and Root, 2020). Furthermore, in animal models, orally administering $\beta$-carotene ( $1 \mathrm{~mL}$ or $15 \mathrm{mg} / \mathrm{kg}$ ) before exposure to cigarette smoke was protective against development of chronic bronchitis induced, by increasing production of NO, clearing oxidative free radicals, and improving chronic inflammation (Pang et al., 2003).

\section{$\alpha$-Carotene}

The risk of childhood asthma is increased by lower levels of serum vitamin $\mathrm{C}$ and $\alpha$-carotene. Asthmatic children have lower serum concentrations of $\alpha$-carotene compared with healthy controls $(2.97 \mathrm{mg} / \mathrm{dL}$ vs. $3.42 \mathrm{mg} / \mathrm{dL})$. Similarly, total carotenoids, including $\alpha$-carotene, in whole blood are significantly lower in asthmatic individuals $(5.69 \mathrm{mg} / \mathrm{d})$ than controls $(8.44 \mathrm{mg} / \mathrm{d})$ (Schock et al., 2003; Harik-Khan et al., 2004; Wood et al., 2005). An earlier study established that serum levels $\alpha$-carotene are significantly associated with decreased risk of cervical dysplasia due to human papillomavirus (HPV) infection [odds ratio $=0.16 ; 95 \%$ confidence interval, 0.04 0.62 (highest vs. lowest tertiles)] (Nagata et al., 1999). Moreover, a study on older dwelling-women aged 65 years and older showed that higher serum $\alpha$-carotene $(257 \mu \mathrm{mol} / \mathrm{L})$ and $\beta$-carotene $(195 \mu \mathrm{mol} / \mathrm{L})$ concentrations (which reflect higher intakes of orange and dark green leafy fruits and vegetables) were independently associated with improved pulmonary function. In addition, $\alpha$-carotene, $\beta$-carotene, and lycopene were associated with improved lung function in Dutch elderly individuals aged 65 to 85 years (Grievink et al., 2000; Semba et al., 2012).

\section{$\beta$-Cryptoxanthin}

A study conducted on ferrets indicated that $\beta$-cryptoxanthin at $104 \mu \mathrm{g} / \mathrm{d}[\sim 1.5 \mu \mathrm{g} / \mathrm{kg}$ body weight (bw) per day in a $70 \mathrm{~kg}$ person] is beneficial against cigarette smokeinduced inflammation, oxidative DNA damage, and squamous lung metaplasia. Indeed, $\beta$-cryptoxanthin reduced TNF- $\alpha$ levels in alveolar, bronchial, bronchiolar, bronchial serous/mucous gland epithelial cells, and in lung macrophages. In addition, $\beta$-cryptoxanthin decreased smokeinduced activation of NF- $\mathrm{KB}$ and AP-1, and levels of 8hydroxy-2'-deoxyguanosine (8-OHdG)-induced oxidative DNA damage in lung tissue (Liu et al., 2011).

\section{Lutein/zeaxanthin}

Lutein/zeaxanhin and their isomer meso-zeaxanthin are pigments in the central region of the retina of the eye that forms the macular pigment (MP), which protects the retina from blue light cytotoxicity and ROS. MP could be utilized against development of age-related macular degeneration by increasing the intake of foods that are rich in lutein/zeaxanthin or by supplementation with lutein/ zeaxanthin (Krinsky et al., 2003). Lutein/zeaxanthin have several beneficial properties, e.g., antioxidant, anti-inflammatory, neuroprotective, autophagy, photo protection, hepatoprotective, immunomodulation, and anti-carcinogenic properties, and improving skin pliability (Woodside et al., 2015; Cho et al., 2018a). A randomized study demonstrated that supplementation with lutein $20 \mathrm{mg} / \mathrm{d}$ for 3 months increased serum lutein levels and decreased serum inflammatory cytokines, such as IL- 6 and MCP-1, serum triglyceride (TG), and low-density lipoprotein (LDL)-cholesterol. These results suggest that protective roles of lutein in atherosclerosis are a result of its anti-inflammatory effects and ability to maintain endothelial function by inhibiting attraction of macrophages (Xu et al., 2013).

In a study of LPS-stimulated macrophages, lutein inhibited LPS-induced NF- $\kappa B$-regulated inflammatory genes (e.g., iNOS, TNF- $\alpha$, IL-1 $\beta$, and COX-2), and decreased intracellular $\mathrm{H}_{2} \mathrm{O}_{2}$ accumulation by scavenging superoxide and $\mathrm{H}_{2} \mathrm{O}_{2}$ (Kim et al., 2008). Likewise, in a study of UV-irradiated keratinocytes, lutein (up to $30 \mu \mathrm{M}$ ) reduced IL-6 from LPS-treated macrophages, COX-2 from IFN- $\gamma /$ TNF- $\alpha$-treated immortalized human keratinocytes and matrix metalloproteinase (MMP)-9 levels. The study suggested that lutein-mediated AP-1 suppression and anti-inflammatory activity results from its strong anti-oxidative and p38/c-Jun N-terminal kinase (JNK) inhibitory activities (Oh et al., 2013). An earlier study indicated that of the 51 carotenoids, $\beta$-cryptoxanthin, lutein, and lactucaxanthin show the strongest inhibitory activities against the Epstein-Barr virus activation in Raji cells (Tsushima et al., 1995). Additionally, lutein suppresses Th2 lymphocyte-mediated airway inflammation in a murine model of asthma. However, the literature suggests a potential positive association between lutein and respiratory health (Song et al., 2012; Melo van Lent et al., 2016).

In addition, a positive connection between $\beta$-cryptoxanthin and lutein/zeaxanthin with pulmonary function was observed in individuals diagnosed with asthma or COPD (Ochs-Balcom et al., 2006). A recent study in rats demonstrated that lutein (at 12.5, 25.0, and $50.0 \mathrm{mg} / \mathrm{kg}$ bw for 28 days) improved oxidative damage markers, such as methane dicarboxylic aldehyde, superoxide dismutase (SOD), NOS, and 8-OHdG, in lung tissues. In addition, lutein reduced inflammatory injury caused by particulate matter $(2.5 \mu \mathrm{m})$ from the air and mediated pro-inflammatory cytokines such as IL-6, IL-8, and TNF- $\alpha$ (Chen et al., 2020b).

\section{Lycopene}

Lycopene attenuated LPS-induced neuro-inflammation and depression-like behaviors in animal models (Zhang et al., 2016). Lycopene ( 25 or $50 \mathrm{mg} / \mathrm{kg}$ ) enhanced recovery of neurological function in rats following spinal cord 
ischemia/reperfusion injury through COX-2 suppression (Hua et al., 2019). The antioxidant and anti-inflammatory properties of lycopene ( 25 or $50 \mathrm{mg} / \mathrm{kg} / \mathrm{d}$ ) are critical for significantly decreasing ROS, leukocytes, lipid peroxidation, and DNA damage produced by cigarettes smoke in mice lungs, and for attenuating pro-inflammatory cytokines, such as TNF- $\alpha$ and INF- $\gamma$ (Campos et al., 2017).

A decreased risk of chronic lung lesions in COPD induced by smoking is associated with a high intake of lycopene $(6.6 \mathrm{mg} / \mathrm{kg}$ bw/d) (Mustra Rakic et al., 2020). Likewise, lycopene ( $\sim 30$ and $\sim 90 \mathrm{mg} / \mathrm{d})$ in human inhibits smoke-induced COPD by decreasing neoplastic lesions and protecting against reverse cholesterol transport-mediated cholesterol accumulation in lungs (Mustra Rakic et al., 2019). A combination of lycopene (100 mg/ $\mathrm{kg}$ ) and matrine (an alkaloid isolated from the traditional Chinese medicine Sophora; $25 \mathrm{mg} / \mathrm{kg}$ ) for 7 days was protective against LPS-induced acute lung injury in mouse (Li et al., 2019). Similarly, adequate intake of lycopene and vitamin A rich foods could be beneficial for asthmatic subjects. In a previous study, treatment with tomato juice and extract reduced airway neutrophil influx. In addition, lycopene reduced allergic inflammation in lungs by decreasing Th2 cytokine (IL-4 and IL-5) responses, indicating its potential as a therapeutic intervention (Riccioni et al., 2007; Wood et al., 2008; Hazlewood et al., 2011). Moreover, an immunopharmacological role of lycopene $(8$ or $16 \mathrm{mg} / \mathrm{kg} / \mathrm{d}$ ) was accompanied by significant inhibition of inflammatory immunocyte infiltration into the bronchoalveolar, decreases in MMP-9 activity, attenuation of eosinophil peroxidase expression, and reduction in increased levels of GATA binding protein 3 (GATA-3) mRNA and IL-4 expressions in an ovalbumin (OVA)-induced murine asthma model (Lee et al., 2008).

Rhinovirus infection, the origin of asthma and the common cold, increases inflammation and inflammatory mediators from airway epithelial cells. Rhinovirus infection was reduced by lycopene treatment $[2.5 \mu \mathrm{g} / \mathrm{mL}$; two times higher than circulating plasma lycopene levels in healthy people $(0.8 \sim 1.34 \mu \mathrm{g} / \mathrm{mL})]$. Furthermore, lycopene decreased IL- 6 and IP-10 levels following exposure of airway epithelial cells to LPS (Saedisomeolia et al., 2009).

\section{Astaxanthin}

Various in vitro and in vivo studies demonstrated the robust anti-oxidant ability of astaxanthin to suppress NF$\kappa \mathrm{B}$ activity and pro-inflammatory cytokines (IL-6, TNF- $\alpha$, IL-1 $\beta$, and PGE2) and restores physiological levels of Src homology 2 domain-containing protein tyrosine phosphatase 1, a protein tyrosine phosphatase that acts as a negative regulator of inflammatory cytokine signaling. In addition, astaxanthin reduces release of ROS and inflammatory cytokines via the MAPK pathway (Kishimoto et al., 2016). Astaxanthin has potential to alleviate the risk of cytokine storm in patients with COVID-19 through different mechanisms, acting via its strong anti-inflammatory and antioxidant properties (Lin et al., 2015; Talukdar et al., 2020). Moreover, astaxanthin stopped in vitro and in vivo pulmonary fibrosis by promoting myofibroblast apoptosis (their numbers correlating with progressive physiological deterioration and injury as well as shortened survival in lungs) by activating dynamin-related protein-1-mediated mitochondrial fission pathway. In addition, astaxanthin inhibits apoptosis in alveolar epithelial cells type II cells by blocking $\mathrm{H}_{2} \mathrm{O}_{2}$-induced ROS formation and prompting cytoprotective gene expression [e.g., caspase-9, caspase-3, and nuclear factor erythroid 2-related factor 2 (Nrf-2)].

Furthermore, a recent study revealed that long noncoding RNA regulated host gene Itgbl1 during pulmonary fibrogenesis (lncITPF) promotes lncRNA (subclass of ncRNA that regulates various essential biological processes and contributes to pathogenesis and development) in lung fibrosis and is blocked by astaxanthin. Therefore, astaxanthin blocks activated fibroblast proliferation and migration through lncITPF and mitochondria-mediated signaling pathways, and alleviates pulmonary fibrogenesis. These data strongly suggest that astaxanthin may be a potential drug candidate for lung fibrosis (Wang et al., 2013; Song et al., 2014; Zhang et al., 2015b; Chen et al., $2020 \mathrm{a})$. Astaxanthin treatment $(60 \mathrm{mg} / \mathrm{kg} / \mathrm{d})$, has a protective influence against ALI in mice by inhibiting the inflammatory response mediated by NF- $\mathrm{kB}$ p 65 , oxidative/ nitrative stress mediated by iNOS and nitro tyrosine, and pulmonary apoptosis by decreasing cecal ligation and puncture-induced mortality (Bi et al., 2017). In addition, the inhibitory effect of astaxanthin on airway inflammation in a mouse model of OVA-induced asthma revealed that astaxanthin $(5,10$, and $50 \mathrm{mg} / \mathrm{kg})$ suppressed total IL-4, and IL-5 (Th2), mediated inflammatory cytokines in bronchoalveolar lavage fluid (BALF) and airway hyperresponsiveness, and increased IFN- $\gamma$ (Th1) levels in BALF. In addition, in OVA-induced asthmatic mice, astaxanthin suppressed infiltration of inflammatory cells in the lung, production of mucus, lung fibrosis, and expression of caspase-1/caspase-3, suggesting that astaxanthin has potential for treating asthma (Hwang et al., 2017).

Astaxanthin has therapeutic potential in the airway inflammatory response associated with COPD. In LPSstimulated RAW264.7 cells, astaxanthin inhibited NO levels, pro-inflammatory mediators and iNOS. Furthermore, in mice exposed to cigarette smoke and LPS, astaxanthin suppressed release of pro-inflammatory cytokines and decreased ROS levels. In addition, in animal models of LPS-induced sepsis and acute lung injury, astaxanthin significantly enhanced survival, protected lungs 
from injury via inhibiting activation of the MAPK/NF- $\kappa B$ pathway, and attenuated LPS-increased inflammatory factors, such as IL- 6 and TNF- $\alpha$, in vitro. Furthermore, astaxanthin reduced the inflammatory response mediated by IL-1 $\beta$, IL- 6 , and TNF- $\alpha$, as well as oxidative damage mediated by malondialdehyde and total SOD in ochratoxin A-induced lung injury in mice by regulating Nrf-2 (antioxidant activity) and NF- $\mathrm{kB}$ (pro-inflammatory activity) pathways. Similarly, astaxanthin directly activates the Nrf-2 pathway, which has preventive effect against cigarette smoke-induced emphysema and COPD in mice. Moreover, astaxanthin reduced lung damage caused by inflammation and hyperoxia by its anti-inflammatory, antioxidant, and anti-apoptotic properties, and protected the pulmonary from severe damage.

These data and other published data show an advantageous role of astaxanthin in protecting against numerous lung diseases by regulating several nuclear factors in NF$\kappa \mathrm{B}$ and MAPK signaling pathways, JAK/STAT signaling pathways, Nrf-2/heme oxygenase-1 (HO-1) signaling pathway, the phosphoinositide 3-kinase/Akt (PI3K/Akt) signaling pathway, and modulates the immune response (Cai et al., 2019; Kubo et al., 2019; Nian et al., 2019; Xu et al., 2019; Akduman et al., 2021; Cheng and Eroglu, 2021).

\section{Crocin and crocetin}

Several studies demonstrated that crocin and crocetin encompass numerous pharmacological activities, including antioxidant, anti-inflammatory, anti-ischemia, anti-viral, anti-cancer, neuroprotective, antihypertensive, anti-hyperlipidemia, anti-atherosclerotic, cardioprotective, antidepressant, memory improvement, antidote, anti-arthritic, and genoprotective activities (Mohamadpour et al., 2013; Soleymani et al., 2018; Luo et al., 2019). Indeed, several in vitro and in vivo studies indicated that crocin alleviates inflammation and pain in various organs, such as lung, heart, brain, and kidney, mainly through inhib-

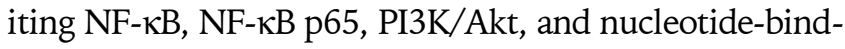
ing oligomerization domain-, leucine rich repeat-, and pyrin domain-containing protein 3 inflammatory pathways (Hashemzaei et al., 2020). Furthermore, crocin (50 $\mathrm{mg} / \mathrm{kg}$ ) pretreatment significantly alleviated and protected against sever lung injury by inhibiting TNF- $\alpha$ and IL-1 $\beta$ production in mice with ALI induced by LPS (1 $\mathrm{mg} / \mathrm{kg}$ ). Wet/dry lung weight ratios, an index of lung edema, and myeloperoxidase (MPO) activities were also reduced by crocin, and the expression of iNOS was significantly suppressed by crocin pretreatment (Wang et al., 2015a). Moreover, crocin $(50 \mathrm{mg} / \mathrm{kg})$ ameliorated COPD induced by cigarette smoke in mice, by suppressing PI3K/ Akt mediated inflammatory pathways. Crocin treatment diminished inflammatory cells, such as macrophages, neutrophils, and lymphocytes, concealed infiltration of peribronchial inflammatory cells, and reduced the concentration of proinflammatory cytokines, including IL-6, TNF- $\alpha$, and IL-1 $\beta$, in BALF and lung tissue. Furthermore, insulin like growth factor 1 , a PI3K activator, revoked the effect of crocin against cigarette smoke-induced activation of the NF- $\mathrm{KB}$ pathway (Xie et al., 2019). In in vitro studies, crocin reduced inflammation of human bronchial epithelial cells induced by Aspergillus fumigatus infection by suppressing NF- $\kappa \mathrm{B}$ signal pathways and inhibiting pro-inflammatory cytokines, such as TNF- $\alpha$, IL-8, IL-6, and IL-1 $\beta$ (Du et al., 2018).

Crocin improved in vitro and in vivo LPS-induced ARDS by protecting against glycocalyx damage in ARDS and by suppressing NF- $\mathrm{KB}$ and MAPK inflammatory signaling pathways. Indeed, crocin effectively enhanced vascular pulmonary edema by maintaining the integrity of glycocalyx in LPS-induced ARDS mice, which affords a pharmacological role of crocin in ARDS treatment (Zhang et al., 2020a). Moreover, a previous study demonstrated that crocin might be a candidate for treatment of asthma by suppressing airway inflammation and hyper-reactivity in a murine model by acting on MAPK signaling pathways. In this study, crocin significantly suppressed airway inflammation and hyper-reactivity, reduced levels of interleukins (IL-4, IL-5, and IL-13) and tryptase in BALF, eosinophil peroxidase in the lung and IgE in serum, and inhibited expression of eotaxin, p-extracellular signal-regulated kinase, p-JNK, and p-p38 in lung (Xiong et al., 2015). Similarly, crocin showed a significant protective effect against allergic asthma progression. Crocin alleviated OVA-induced allergic asthma-associated alterations in inflammatory and oxidative stress biomarkers by enhancing antioxidant defenses, reducing the incidence of oxidative stress, and restored pro-inflammatory cytokines (e.g., TNF- $\alpha$ ) to normal levels, and modulating IL-4/IL13 pathways, which enhances Th2-mediated immune reactions (Yosri et al., 2017). In addition, saffron with its major compounds crocin and safranal decrease airway hyper-responsiveness and airway cellular infiltration to the lungs as well as reduced iNOS production, bronchial epithelial cell apoptosis, and Th2 type cytokine production in inflamed lungs of mice, which attenuates asthma (Bukhari et al., 2015). Crocetin alleviates OVA-induced asthma in mice by increasing forkhead box P3 (Foxp3, a protein involved in immune system responses and a crucial regulator of regulatory $\mathrm{T}$ cells) and the number of Treg cells in the lung. Crocetin is protective against LPSinduced ALI by reducing NF- $\mathrm{KB}$ activity, and decreasing LPS-induced mRNA and protein expression of IL-6, MCP1 , and TNF- $\alpha$ in lung tissue (Yang et al., 2012; Ding et al., 2015). Furthermore, an in vitro study demonstrated that crocin and picrocrocin from saffron could be promising anti-herpes simplex virus type 1 (HSV-1) and antihuman immunodeficiency virus (HIV) agents against vi- 
ral infections (Soleymani et al., 2018).

\section{Phytoene and phytofluene}

Phytoene and phytofluene have not been associated with health benefits in epidemiological studies as they are not included in food databases. However, several in vitro and in vivo studies as well as human studies have demonstrated their health benefits (e.g., antioxidant, ant-inflammatory properties, and their roles in decreasing DNA damage in lymphocytes and protecting skin against leukemia, and breast and prostate cancers). Phytoene and phytofluene are predominantly found in human plasma, milk, and other tissues such as skin (Meléndez-Martínez et al., 2015; Havas et al., 2018). These carotenoids strongly enhance antioxidant activity of coenzyme Q10 (CoQ10) in human dermal fibroblast cell cultures and protect CoQ10 from degradation by ROS and hypochlorite. Moreover, phytoene and phytofluene enhance inhibition of Q10 against three inflammatory mediators, PGE2, IL-6, and MMP-1 (Fuller et al., 2006).

An algal preparation containing phytoene and phytofluene isolated from Dunaliella bardawil demonstrated inhibition of LDL oxidation in vitro. Thus, phytoene and phytofluene may be part of the defense system against oxidative stress (Shaish et al., 2008). Despite the several benefits of these carotenoids, which traditionally coexist with lycopene in food, they are often ignored from studies due to lower bioavailability vs. other carotenoids and the safe use of phytoene and phytofluene-rich products in current applications (Mapelli-Brahm et al., 2017; Havas et al., 2018). Therefore, it is rare to find an in vitro, in vivo, or human study that describes the roles of these colorless carotenoids and their mechanisms of action.

\section{Fucoxanthin}

Fucoxanthin has a unique structure involving an unstable allenic bond and nine conjugated double bonds, and exhibits strong antioxidant activity. Fucoxanthin shows several biological and pharmaceutical properties, including anti-inflammatory, anti-cancer, anti-obesity, anti-diabetes, hepatoprotective, cardiovascular and cerebrovascular protective, hepatoprotective, antiangiogenic, antimalaria, and anti-bacterial properties (Zhang et al., 2015a; Karpiński et al., 2019). Previous studies have demonstrated the ability of fucoxanthin to inhibit transcription factor pathways, including NF- $\mathrm{KB}$ and MAPK pathways, and reduce levels of pro-inflammatory mediators, such as NO, PGE2, IL-1 $\beta$, TNF- $\alpha$, IL-6, iNOS, and COX-2 (Peng et al., 2011; Zhang et al., 2015a). A recent study revealed that fucoxanthin, isolated for the first time from Conticribra weissflogii ND-8, has strong anti-inflammatory effects on mouse models of sepsis. Fucoxanthin $(0.1 \sim 1.0 \mathrm{~mL} / \mathrm{kg})$ reduces pro-inflammatory cytokines, such as IL- 6 , IL-1 $1 \beta$, and TNF- $\alpha$, in a prophylactic man- ner in sepsis induced by LPS $(20 \mathrm{mg} / \mathrm{kg})$. Furthermore, the $50 \%$ inhibitory concentration (IC ${ }_{50}$ ) inhibitory effect of fucoxanthin on NF- $\mathrm{kB}$ was about $11 \mu \mathrm{M}$, and the $\mathrm{IC}_{50}$ inhibitory effect on pro-inflammatory IL-6 production was about $2 \mu \mathrm{M}$ in macrophage cells (Su et al., 2019). Fucoxanthin $(50 \mathrm{mg} / \mathrm{kg})$ showed significant protective activity against OVA-induced asthma in mice by efficiently decreasing intracellular secretion of ROS and increasing antioxidant enzyme activities. In addition, fucoxanthin decreased pro-inflammatory cytokines in BALF, suggesting that fucoxanthin may be a potential anti-asthma drug in human (Yang et al., 2019).

A previous study showed that fucoxanthin is effective against pulmonary fibrosis. Fucoxanthin inhibited TGF$\beta 1$-induced expression of alpha-smooth muscle actin ( $\alpha$ SMA), type 1 collagen, fibronectin, and IL- 6 in human pulmonary fibroblasts (HPFs), and inhibited TGF- $\beta 1$-induced phosphorylation of p-38 MAPK, PI3K/Akt, and Smad2/Smad3. Furthermore, fucoxanthin significantly reduced collagen contraction. In addition, intraperitoneal injection of fucoxanthin $(10 \mathrm{mg} / \mathrm{kg})$ inhibited bleomycininduced pulmonary fibrosis and type I collagen protein expression in mice (Ma et al., 2017). A more recent study demonstrated that fucoxanthin markedly increased nuclear translocation of Nrf-2 in LPS-treated macrophages, which significantly attenuated LPS-induced ROS accumulation and expression of pro-inflammatory cytokine (including IL-6, IL-1 $\beta$, and TNF- $\alpha$ ) (Kim et al., 2021).

\section{CAROTENOIDS ENHANCE IMMUNITY FACING COVID-19 AND RELATED SYMPTOMS}

The primary host immune response to SARS-CoV-2 infection and the obliteration of lung tissue damage is characterized by macrophage/monocyte and neutrophil recruitment, cytokine (i.e., IL-2, IL-6, granulocyte-colonystimulating factor, IFN- $\gamma$, IP-10, MCP-1, MCP-3, MIP-1 $\alpha$, and TNF- $\alpha$ ) release, adaptive immune response stimulation, and adaptive $\mathrm{T}\left(\mathrm{CD} 4^{+}\right.$and $\mathrm{CD} 8^{+} \mathrm{T}$ cells) and $\mathrm{B}$ cells. In general, innate and adaptive immune processes eradicate COVID-19 disease. However, when the immune system cannot appropriately function (such as due to individual responses to viral loads during primary SARSCoV-2 infection), dysfunctional immune responses can lead to cytokine overproduction. This can result in increased viral replication and lung tissue damage, functional lung injury, reduced lung capability, and even systemic pathology and multi-organ failure (including of the heart, kidney, and gastrointestinal tract) (Catanzaro et al., 2020; Perico et al., 2021). In clinically severe cases of COVID-19, individuals experience noticeable decreases in total numbers of $\mathrm{CD} 4^{+}$cells, $\mathrm{CD} 8^{+}$cells, B cells, and NK cells, and decreases in monocytes, eosinophils, and 
basophils (Catanzaro et al., 2020; Tay et al., 2020). CD ${ }^{+}$ cells are important for attacking and killing viral infections, whereas $\mathrm{CD} 4^{+}$cells are vital for both $\mathrm{CD} 8^{+} \mathrm{T}$ cells and $\mathrm{B}$ cells. $\mathrm{CD} 4^{+} \mathrm{T}$ cells are also responsible for cytokine production to drive immune cell recruitment. Both $\mathrm{CD} 4^{+}$ and $\mathrm{CD}^{+}$cells signified strong predictive values for severity and mortality of hospitalized COVID-19 patients (Catanzaro et al., 2020). In addition, it has been reported that SARS-CoV-2 inhibits components of host immunity, such as increased levels of exhausted $\mathrm{CD} 8^{+} \mathrm{T}$ cells and loss of $\mathrm{CD}^{+} \mathrm{T}$ cell function, sloping towards $\mathrm{Th} 17$ in the peripheral blood (Tay et al., 2020). In the early stage of infection, SARS-CoV-2 impairs and even suppresses the immune system, and damages tight junctions in lung tissues, whereas the severe stage might involve activated immune responses, which leads to a cytokine storm and multi-organ damage. Therefore, enhancing the balanced host immune response against pathogens, in particular SARS-CoV-2, by adaptive and innate immune responses is vital for controlling and eradicating infections (Tian et al., 2020).

Incidentally, carotenoids have shown several worthy immune roles. Herein, we report the most well-known carotenoids as immune promoters in several studies found in relevant literature.

\section{$\beta$-Carotene}

$\beta$-Carotene $(20,40$, and $60 \mathrm{mg} / \mathrm{kg}$ bw orally for 30 days) decreases liver tissue damage and improves the immune function of hepatocellular carcinoma (HCC) rats by inhibiting tumor growth (Cui et al., 2012). $\beta$-Carotene (5 $\mu \mathrm{M}$ or $10 \mu \mathrm{M}$ for $2 \mathrm{~h}$ ) exhibits anti-inflammatory effects by inhibiting pro-inflammatory adipokines regulated by NF- $\mathrm{kB}, \mathrm{AP}-1$, and signal transducer and activator of transcription-3 pathways, such as MCP-1, normal T cell expressed, and presumably secreted chemokines (RANTES or CCL5). Thus, $\beta$-carotene enhanced adiponectin in adipocytes by ceasing oxidative stress-induced inflammation, which is related to adipokine dysfunction (Cho et al., 2018b). A pilot study indicated that $\beta$-carotene increased $\mathrm{CD}^{+}$cell population in patients with acquired immunodeficiency syndrome, which enhances immunological function. Similarly, $\beta$-carotene treatment $(60 \mathrm{mg} / \mathrm{d}$ for 25 36 months) significantly increased blood CD $4^{+}$ and $\mathrm{CD} 8^{+}$lymphocytes and reduced other HIV symptoms in patients with HIV (Fryburg et al., 1995; Milani et al., 2017). Low serum concentrations of $\beta$-carotene, retinol and vitamin $E$ have been reported in children with HIV in Brazil, Argentina, and Mexico. Another study indicated that $\beta$-carotene modulates certain immune markers in HIV-infected subjects. In addition, an observational study in Kenyan women concluded that low serum $\beta$-carotene concentrations reflect more active HIV-1 infections (Garewal et al., 1992; Baeten et al., 2007; Monteiro et al., 2009). Moreover, anti-inflammatory activities of $\beta$-carotene against have been demonstrated against the human herpes simplex virus due to its ability to inhibit proinflammatory mediators, such as NO, IL-1 $\beta$, IL- 6 , and MCP-1, and suppress the sub-units p50 and p65 of NF$\kappa B$ (Lin et al., 2012).

\section{$\alpha$-Carotene}

$\alpha$-Carotene has antioxidant and possible anti-carcinogenic and immune enhancing properties. Some epidemiological studies noted that a higher $\alpha$-carotene intake is associated with lower risk of cardiovascular disease (CVD) and cancer (Tanumihardjo, 2013). In addition, a nutritional survival study demonstrated that serum $\alpha$-carotene concentrations are inversely associated with the risk of death from all causes, including CVD and cancer ( $\mathrm{Li}$ et al., 2011). In the human neuroblastoma cell line GOTO, $\alpha$-carotene inhibits proliferation 10 times more than $\beta$ carotene, acting via reducing mRNA levels of the protooncogene protein N-myc (Murakoshi et al., 1989). $\alpha$-Carotene, but not $\beta$-carotene, can reduce lung tumor numbers, and $\alpha$-carotene has a stronger effect than $\beta$-carotene on suppressing the activity of 12-O-tetradecanoylphorbol-13-acetate on skin carcinogenesis in a mouse model. In addition, $\alpha$-carotene alongside lycopene is inversely associated with risk of prostate cancer (although not at the advanced stage), suggesting that $\alpha$-carotene plays an important role in cancer prevention (Murakoshi et al., 1992; Wang et al., 2015b). Additionally, $\alpha$-carotene shows anti-metastatic activity in Lewis lung carcinoma in vitro by inhibiting invasion, migration, activities of MMP-2, MMP-9, urokinase plasminogen activator, and integrin 31 -mediated phosphorylation of focal adhesion kinase, which decreases phosphorylation of the MAPK pathway. This study also indicated that $\alpha$-carotene in combination with taxol has a strong effect on lung metastasis and effectively inhibits Lewis lung carcinoma, suggesting that $\alpha$-carotene could be used as an anti-metastatic agent or as an adjuvant for anti-cancer drugs (Liu et al., 2015).

A longitudinal study indicated that serum $\alpha$-carotene concentrations are inversely associated with all measures of body composition (e.g., body mass indices, fat mass, and lean mass) in a group of women aged 19 50 years, showing a clear association between $\alpha$-carotene and body fatness of the studied group, and which appears to go beyond simply fat-soluble properties (Nuss et al., 2017). Furthermore, another cohort studying patients during the year following hip fractures indicated that higher baseline and time-varying $\alpha$-carotene and time-varying lutein concentrations are associated with lower pro-inflammatory mediators, such as soluble TNF- $\alpha$ receptor 1 and IL-16, at post-fracture visits (D'Adamo et al., 2012). 


\section{$\beta$-Cryptoxanthin}

$\beta$-Cryptoxanthin is an important precursor of vitamin A, and has several functions important for human growth, vision, development, and immune function. $\beta$-cryptoxanthin is readily absorbed from its major food sources at a rate probably greater than that of other common carotenoids, and may provide a generous amount of vitamin A, equivalent to the amount of vitamin A from $\beta$-carotene (Burri, 2015; Burri et al., 2016). $\beta$-Cryptoxanthin has demonstrated various beneficial activities, such as antioxidant, anti-obesity, anti-inflammatory, anti-osteoporosis, and anti-cancer activities (Burri et al., 2016; Jiao et al., 2019). Furthermore, $\beta$-cryptoxanthin prevents nonalcoholic steatohepatitis (NASH) in mice by reducing expression of M1 and M2 macrophages, T helper cells and cytotoxic T cells, suppresses expression of LPS-inducible and/or TNF- $\alpha$-inducible genes in NASH, and decreases thiobarbituric acid reactive substances, markers of oxidative stress, which is considered a major mechanism of inflammation in liver. Thus, $\beta$-cryptoxanthin is effective in inhibiting inflammatory gene expressions in NASH. Moreover, $\beta$-cryptoxanthin reverses steatosis, inflammation, and fibrosis through an M2-dominant shift in macrophages/Kupffer cells in the liver of NASH mice (Kobori et al., 2014; $\mathrm{Ni}$ et al., 2015). $\beta$-Cryptoxanthin $(2.5 \mathrm{mg} / \mathrm{kg}$ bw for 12 weeks) reduces cardio-metabolic and inflammatory markers in high-fat diet rats by down-regulating $\mathrm{NF}-\kappa \mathrm{B}$ and TNF- $\alpha$ and up-regulating Nrf-2, HO-1, and peroxisome proliferator-activated receptor (PPAR) alpha pathways (Sahin et al., 2017). Several epidemiological studies have shown inverse associations between serum $\beta$-cryptoxanthin and the risks for atherosclerosis, insulin resistance, liver dysfunction, metabolic syndrome, low bone mineral density, and oxidative stress (Sugiura, 2015). In vitro, protective effects of lutein and $\beta$-cryptoxanthin against human chondrocyte dysfunction were demonstrated by scavenging ROS required for NF- $\mathrm{\kappa B}$ activation and inhibiting pro-inflammatory responses induced by $10 \mu \mathrm{g}$ of IL-1 $\beta$ (Di Filippo et al., 2012). In both in vitro and in vivo studies, $\beta$-cryptoxanthin demonstrated a potentially beneficial effect on health and on preventing immunity of related diseases by increasing $\mathrm{CD} 4^{+}$lymphocytes and serum IgG, IgM, and IgA levels in mammals (Di Filippo et al., 2012; Ghodratizadeh et al., 2014). Indeed, a study demonstrated that ingestion of a few kumquats, which mainly contain a cyclic monoterpene (R-limonene) and $\beta$-cryptoxanthin, on a daily basis could help combat stress and enhance NK cell activity, which plays an important role in innate immunity by eliminating cancer cells and cells infected with viruses (Terao et al., 2019).

\section{Lutein}

Lutein increases the percentage of $\mathrm{CD} 4^{+}, \mathrm{CD} 21^{+}, \mathrm{CD} 5^{+}$, and $\mathrm{CD}^{+}$lymphocytes, MHC II molecules, and plasma IgG and IgM, inducing the immuno-modulatory action of lutein in domestic animals (Kim et al., 2020a; Kim et al., 2020b). Moreover, lutein is the major carotenoid in yellow cocoons of Bombyx mori silkworms, exhibiting in vivo immune enhancement activities by increasing $\mathrm{NK}$ cell activity, $\mathrm{CD}^{+}, \mathrm{CD}^{+}$, and $\mathrm{CD}^{+}$cell populations, and IL-2 and IFN- $\gamma$ production. This suggests that lutein treatment plays an important role in reinforcing immunity (Promphet et al., 2014).

\section{Lycopene}

Several studies have indicated that lycopene and consumption of lycopene in diet could affect susceptibility to cancer, cardiovascular disease and diabetic complications through enhancing antioxidant enzyme activities and immunity function (Neyestani et al., 2007; Story et al., 2010; Luo and $\mathrm{Wu}, 2011)$. Moreover, lycopene $10 \mu \mathrm{m}$ has immunopharmacology effects in inhibiting dendritic cells maturation induced by LPS in murine bone marrow through inhibiting MAPK and NF- $\mathrm{kB}$ p65 translocation pathways (Kim et al., 2004). Indeed, treatment with lycopene $10 \mathrm{mg} / \mathrm{kg}, 20 \mathrm{mg} / \mathrm{kg}$, and $40 \mathrm{mg} / \mathrm{kg}$ for 28 days improves the immune status of diabetic rats by decreasing neutrophil count, low neutrophil-lymphocyte ratios, and platelet counts, and by stabilizing albumin-globulin levels (Eze et al., 2019).

Another study demonstrated protective roles of lycopene at $10 \mathrm{mg} / \mathrm{kg}$ for 10 days in rat intestinal injury induced by methotrexate, acting by reducing the elevated oxidative stress and pro-inflammatory cytokine (IL-1 $\beta$ ) levels (Yucel et al., 2016). Furthermore, tomato lycopene extract inhibits intestinal inflammation induced by LPSinduced proinflammatory gene expression by blocking NF-kB signaling (Joo et al., 2009). In addition, lycopene at $0.3 \%$ mixed into a high-fat and high-fructose western diet 10 weeks induces cognitive impairments in a mouse model by improving insulin resistance, lipid metabolism dysfunction, and inflammatory responses in the gut-liver-brain axis, suggesting that lycopene may be a nutritional strategy for Western diet-induced dysfunction of the central nervous system (Wang et al., 2019a). Moreover, lycopene at $50 \mathrm{mg} / \mathrm{kg}$ bw/d for 40 days ameliorates dextran sulfate sodium-induced gut barrier damage and inflammatory responses in mice by mediating the microbe-gut-brain axis balance (Zhao et al., 2020).

In addition, lycopene at $10 \mu \mathrm{M}$ exerts potential beneficial effects on skeletal muscle metabolism by its effects on the activities of metabolic enzymes in muscle fibers, which promotes expression of slow-twitch fibers and enhances mitochondrial respiratory capacity (Liu et al., 2021).

\section{Astaxanthin}

A randomized double-blinded, placebo-controlled study 
concluded that dietary astaxanthin at 2 and $8 \mathrm{mg}$ for 4 or 8 weeks decreases DNA damage biomarkers and acute phase proteins, and enhances immune responses in young healthy females approximately 21.5 years of age. Furthermore, astaxanthin decreases plasma CRP concentrations. In addition, dietary astaxanthin stimulates mitogen-induced lymph proliferation, increases NK cell cytotoxic activity, and increases total $\mathrm{T}$ and $\mathrm{B}$ cell subpopulations (Park et al., 2010). Similarly, astaxanthin reveals antioxidant and anti-inflammatory activities, and boosts immune responses in humans. Indeed, supplementation of healthy adult females with 2 and $8 \mathrm{mg} / \mathrm{d}$ of astaxanthin for 8 weeks diminished levels of oxidative damage biomarkers and inflammation, and enhanced immune responses (Kishimoto et al., 2016).

In primary cultured lymphocytes, astaxanthin demonstrates immunomodulatory effects both in vitro and ex vivo by increasing production of INF- $\gamma$ and IL-2 cytokines without inducing cytotoxicity. Furthermore, astaxanthin enhances immune responses in mice by increasing INF- $\gamma$, IL-2, and IL-10 in response to Helicobacter pylori infection (Lin et al., 2015; Davinelli et al., 2019). In a previous study, astaxanthin administered daily at two doses (20 $\mathrm{mg} / \mathrm{kg}$ and $40 \mathrm{mg} / \mathrm{kg}$ ) for 14 days reduced serum liver enzymes and pathological damage in mice treated with concanavalin A-induced $25 \mathrm{mg} / \mathrm{kg}$ murine autoimmune hepatitis. Astaxanthin acted by reducing release of inflammatory factors such as NF- $\mathrm{kB}$ p65, IL-6, IL-1 $\beta$, and IFN- $\gamma$ through reducing JNK/p-JNK-mediated apoptosis and autophagy by blocking interactions between TNF- $\alpha$ and TNF receptor-associated factor 2 . In addition, astaxanthin demonstrates an anti-apoptotic effect by decreasing phosphorylation of B-cell lymphoma 2 through downregulating the JNK/p-JNK pathway, suggesting that astaxanthin may be a promising potential therapeutic agent against autoimmune diseases (Li et al., 2015).

In rats, astaxanthin significantly reduces pro-inflammatory mediators, including IL- $1 \beta$, IL- 6 , NF- $\mathrm{kB}$ p 65 , and $\mathrm{I} \kappa \mathrm{B} \alpha$, and increases levels of IL-2, IgM, and IgG, suggesting that astaxanthin ameliorates oxidative stress and improves immune impairment (Chen et al., 2020c). Zhang and colleagues recently demonstrated that administration of astaxanthin (60 and $120 \mathrm{mg} / \mathrm{kg} / \mathrm{bw}$ ) in cyclophosphamide-induced immunodeficient mice effectively prohibited intestinal mucosa damage, by reducing oxidative stress levels, increasing intestinal morphological structural integrity, stimulating goblet cells growth and mucous secretion, decreasing development of Paneth cells and expression levels of antimicrobial peptides, increasing IgA secretion, and ameliorating main gut flora (especially total bacteria, Lactobacillus and Enterobacteriaceae spp.) and its metabolites (acetic acid, propionic acid, and butyric acid). In addition, astaxanthin enhanced intestinal mucosal barriers, which is of a role of great significance in maintaining immune function in the body (Zhang et al., 2020b).

In bleomycin-induced pulmonary fibrosis, astaxanthin at $2 \mathrm{mg} / \mathrm{kg}$ has anti-fibrotic effects, both in vitro and in vivo. Indeed, in vivo, astaxanthin significantly enhances the structure of alveoli, alleviates collagen deposition, and reduces levels of $\alpha$-SMA, vimentin (intermediate filament expressed in a variety of cells, including lymphocytes and neutrophils), hydroxyproline (a major component of the protein collagen), and B cell lymphoma/leukemia-2. In addition, astaxanthin may increase E-cadherin and cellular tumor antigen p53 protein expression in vitro and in vivo (Zhang et al., 2015b).

\section{Crocin and crocetin}

Saffron is used in traditional medicine for treatment of various conditions, including coughs, stomach disorders, amenorrhea, asthma, and cardiovascular disorders (Mokhtari-Zaer et al., 2015). Most of the pharmacological activities of saffron are related to the presence of carotenoids (crocin and crocetin). Saffron inhibits serum levels of NF-KB p65 unit, and pro-inflammatory mediators, including TNF- $\alpha$, IFN- $\gamma$, IL-1 $\beta$, IL-6, IL-12, and IL-17A, and is an agonist of PPAR- $\gamma$, which has inhibitory effect on NF- $\kappa \mathrm{B}$. Furthermore, saffron reduces key pro-inflammatory enzymes, such as MPO, COX-2, iNOS, phospholipase A2, prostanoids (a subclass of eicosanoids), and adhesion molecules including intercellular adhesion molecule, vascular cell adhesion molecule, and E-selectin. In addition, saffron modulates MAPK and NF- $\mathrm{KB}$ pathways. Therefore, saffron and its components could have a promising role in treatment of immune disorders (Zeinali et al., 2019).

\section{Fucoxanthin}

Fucoxanthin has an immunoregulatory role as an anti-inflammatory agent. In vivo, suppression of antigen-induced aggregation of the high affinity IgE receptor (FceRI) and FceRI-mediates degranulation signals of mast cells. Fucoxanthin inhibits degranulation of mast cells by suppressing aggregation of FceRI (Sakai et al., 2009; Zhang et al., 2015a). A methanol extract of Undaria pinnatifida, which contains a bioactive amount of fucoxanthin, demonstrates anti-edema, and anti-erythema effects with relative inhibition ratios of $85 \%$ and $78 \%$, respectively, against mouse ear edema and erythema induced by phorbolmyristate acetate. In addition, the extract demonstrates antipyretic effects in yeast-induced hyperthermic mice (Peng et al., 2011). 


\section{CAROTENOIDS AS POTENTIAL ANTIVIRAL AGENTS}

Microalgae extracts traditionally used as food are rich in carotenoids source, such as Haematococcus pluvialis (source of astaxanthin 0.2 2.0\%/dry weight) and Dunaliella salina ( $\beta$-carotene $400 \mathrm{mg} / \mathrm{m}^{2}$ from cultivated area) show antiviral activity in vitro (African green monkey kidney cell) against HSV-1 at different stages of viral infection. However, this study and other similar studies suggest that the anti-viral activity of microalgae extracts may related to its polysaccharide compounds (Santoyo et al., 2012). A recent study demonstrated that Haloarchaea, such as $\mathrm{Na}$ trialba sp., are good candidates for carotenoid production (such as astaxanthin, lutein, canthaxanthin, bacterioruberin, and salinixanthin). Indeed, in vitro, the extracted pigment exhibited significantly stronger ability to eliminate hepatitis $\mathrm{C}$ virus (HCV) and hepatitis B virus (HBV) in infected human blood mononuclear cells than currently used drugs. The pigment inhibits both polymerase-dependent HCV and HBV replication (Hegazy et al., 2020).

Carotenoids, such as lutein, zeaxanthin, and carotene, in plasma also have potential antiviral roles (Iddir et al., 2020). Lutein demonstrates in vitro antiviral activity against HBV infection. Lutein inhibits the activity of the HBV full-length promoter through inhibiting the HBV transcription cycle. This mechanism of action is supported by a docking study that demonstrated a promising role of lutein a future anti-viral drug against the nonstructural protein 3 of the HCV helicase that is essential for viral replications (Pang et al., 2010; Fatima et al., 2014).

Crocetin improves host responses to dengue virus (DENV)-induced liver injury. In the liver of DENV-infected mice, crocetin reduces DENV-induced oxidative stress, pro-inflammatory responses and NF- $\mathrm{KB}$ (both NF$\kappa B$ p65 and NF- $\mathrm{B}$ p50) translocation. However, crocetin does not inhibit DENV replication but improves host responses that reduce liver injury. In addition, crocetin, ergosterol peroxide, and $\kappa$-carrageenan have demonstrated strong bonding to both HPV-16 and HPV-18 (strains 16 and 18 of HPV are the most common) in mucosal epithelium. Thus, these compounds could represent further anti-viral drugs (Sreekanth et al., 2020; Meza-Menchaca et al., 2021).

Crocin and picrocrocin (a derivative from zeaxanthin that is responsible for the taste of saffron) are the major components of saffron extract, indicate significant antiHSV-1 and anti-HIV-1 activities in vitro. Crocin inhibits HSV replication before and after entry into Vero cells. Indeed, crocin suppresses HSV penetration into target cells and disturbs viral replication after entry into cells. Picrocrocin is also effective at inhibiting viral entry and replication, suggesting that crocin and picrocrocin could be promising anti-HSV and anti-HIV herbal therapy agents against viral infections (Soleymani et al., 2018).

In addition, a molecular docking study demonstrated that crocin, digitoxigenin, and $\beta$-eudesmol were three of 67 compounds found in medicinal plants from Morocco that effectively inhibit the main protease of SARS-CoV-2, determined by the energy of the interactions between these molecules and the studied protein of the COVID-19 receptor. The in vitro and in vivo activity demonstrated in this study suggests that these molecules could target the major SARS-Cov-2 protease (Aanouz et al., 2021). Moreover, astaxanthin can reduce binding of HPV to cell membranes of human sperm in vitro by about $50 \%$ through inhibiting HPV-late protein 1 (L1, involves in structural component of viral capsid), expressed during initial stages of infection to binding to membranes (Donà et al., 2018).

Recent network pharmacology and molecular docking analyses was conducted on the traditional Chinese herb Lianhua Qingwen capsule (LQC), which is composed of 13 components. LQC is usually used to prevent and treat viral influenza (e.g., H1N1) in China and has shown some effectiveness for COVID-19 treatment, both in clinical surveillance and in randomized controlled trials. After molecular docking, 6 molecules directly interact with Akt1, including $\beta$-carotene, kaempferol, luteolin, naringenin, quercetin, and wogonin. Akt1, a serine/threonine protein kinase (Akt kinase), plays a vigorous role in easing viral infections (including SARS-CoV-2) and could be an ideal therapeutic agent with a wide range of antiviral effects, with its overexpression shown to promote viral protein synthesis. Thus, these six compounds, including $\beta$-carotene, could be potential agents for COVID-19 treatment by inhibiting Akt1 pathways. Furthermore, the study suggested synergistic effects of these molecules (Xia et al., 2020).

Similarly, a molecular docking study was conducted on buriti oil (Mauritia flexuosa L.), a natural product extracted from the fruit of the palm in Brazil. Carotenoids are the main constituents of buriti oil, and include $\beta$-carotene (and $\beta$-carotene depravities such as 13-cis- $\beta$-carotene 9cis- $\beta$-carotene), $\alpha$-carotene, phytofluene, and zeaxanthin. One study focused on the main peptidase of SARS-CoV (PDB ID: 2GTB), which is similar (96\%) to the main SARS-CoV-2 peptidase that caused the COVID-19 pandemic. 2GTB has an important role in the viral life cycle. Results of molecular docking analysis revealed promising interaction energies in formation of complexes between 2GTB with 13-cis- $\beta$-carotene ligands $\left(\Delta_{\text {Gbind }}=\right.$ $-10.23 \mathrm{kcal} / \mathrm{mol})$, 9 -cis- $\beta$-carotene $\left(\Delta_{\text {Gbind }}=-9.82 \mathrm{kcal} /\right.$ $\mathrm{mol})$, and $\alpha$-carotene $\left(\Delta_{\text {Gbind }}=-8.34 \mathrm{kcal} / \mathrm{mol}\right)$. The study demonstrated substantial interactions of these ligands, with an emphasis on $\alpha$-carotene, and suggested possible in vitro and in vivo experiments for detecting new drugs with inhibitory enzymatic action against COVID- 
19 (Costa et al., 2021).

\section{CONCLUSIONS AND PERSPECTIVES}

Carotenoids are a group of naturally occurring pigments that possess several health benefits. Carotenoids have advantageous pharmacological and biological effects and may be directly implicated in several cellular and molecular pathways related to inflammatory processes, which likely reflect their favorable protective nature against inflammation and oxidative damage as well as their immune modulation capability. Despite the fact that carotenoids are one of the major groups of phytochemicals in human diets and are diverse in nature, data about their effects against human viral diseases are still erratic and mixed compared to their counterparts, such as polyphenolic compounds, which are intensively studied (Khalil and Tazeddinova, 2020). Most studies reported that consumption of carotenoids from their natural sources is safe and efficacious. However, others reported a risk of $\beta$-ca- rotene supplementation with some lung cancers, particularly in smokers. Nevertheless, a meta-analysis revealed that both dietary intake and circulating levels of $\beta$-carotene are inversely associated with the risk of all-cause mortality, mainly dietary $\beta$-carotene, and that it has a protective effect on preventing non-communicable chronic diseases (Furman et al., 2019). Carotenoids could be utilized as potential drugs for combating against COVID19 by targeting the inflammatory storm resulting from viral infections. In addition, diets rich in carotenoids may protect against progression of inflammation related to the acute phase of COVID-19, preventing disease progression, principally among elderly individuals. Previous studies have shown that older individuals have higher circulating levels of cytokines, chemokines, and acute phase proteins, and higher expression of genes involved in inflammation (Zhao et al., 2016), which may partly explain why elderly individuals have the highest risk of COVID-19 infection. Carotenoids also play an imperative role in boosting body immunity, mainly through their effects on several antioxidant and anti-inflammatory path-

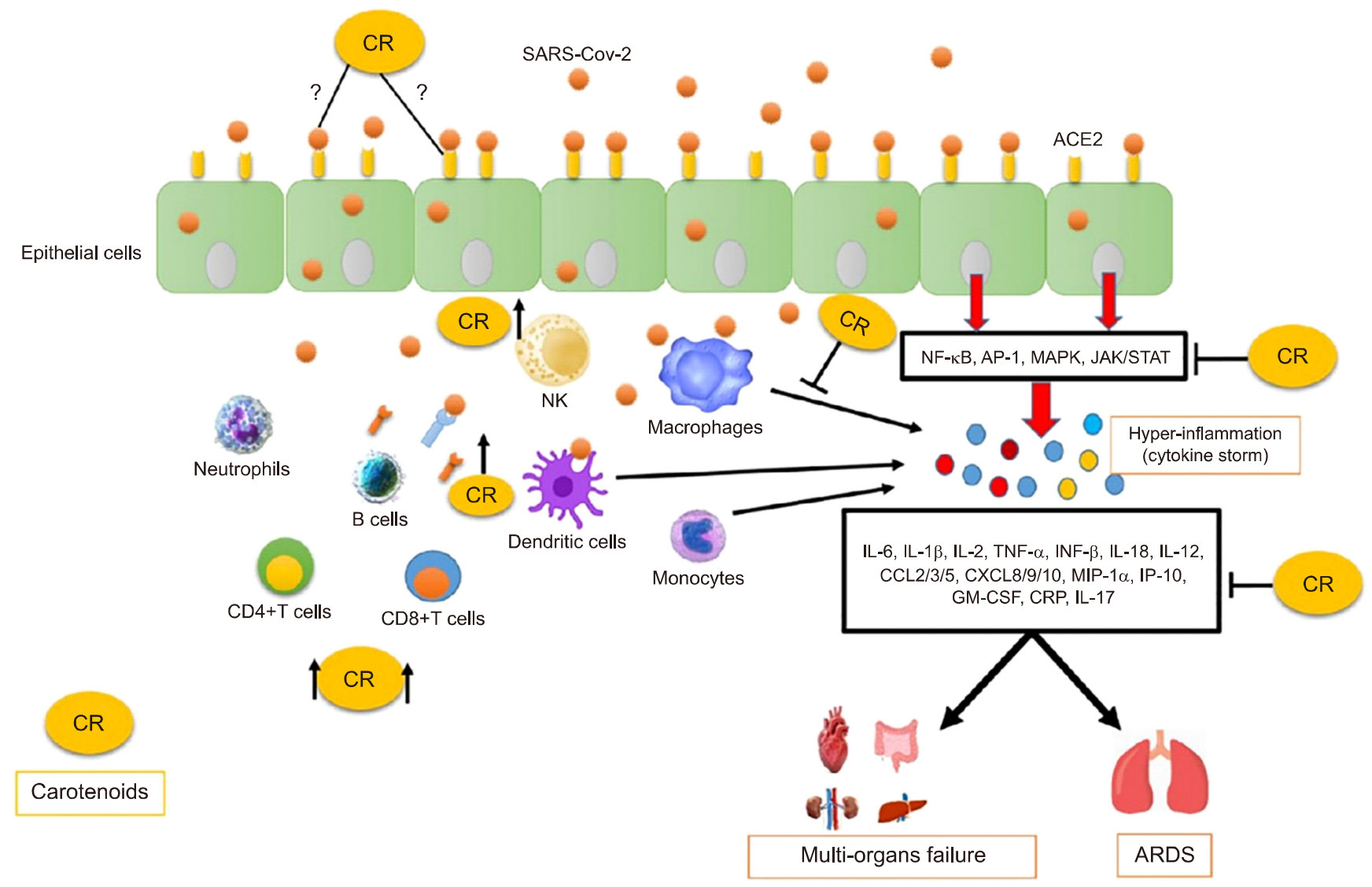

Fig. 3. Proposed protective mechanisms of carotenoids (CR) during COVID-19 and related symptoms. When the SARS-CoV-2 invades the host, the virus actives NF- $\mathrm{BB}$ and MAPK signaling pathways either in the infected cells or in the immune responsive cells such as dendritic cells and macrophages, which results in an excessive inflammatory response mediated by an extra production of pro-inflammatory cytokines and hyperinflammation (cytokine storm). This accumulation plays a substantial role in the COVID-19 pathogenesis and can lead to acute respiratory distress (ARDS) and multi-organs failure. CR could inhibit these main signaling pathways as well as the overproduction of inflammatory cytokines. Followed by the SARS-CoV-2 infection, which contributes to immune system perturbations such as exhaustion and a decrease number of the total number of $\mathrm{CD} 4^{+} \mathrm{T}$ cells, $\mathrm{CD} 8^{+} \mathrm{T}$ cells, IgE, IgM, and natural killer (NK) cells. CR increase the total number of these immune cells and enhance the immune system. CR could have anti-viral properties, which has to be elucidate in experimental. 
ways and on components of the immune response. Thus, carotenoids may have roles as immune-enhancers against CVOID-19 and other emerging diseases and related syndromes (Fig. 3). Alternative therapeutic strategies based on available foods and plants have been shown to alleviate similar infections (Fasogbon et al., 2021). Therefore, carotenoids from natural resources or supplements may be future therapeutic strategies against these viral diseases. However, further research and clinical trials must be conducted before conclusions can be drawn.

This review suggests that the first and the most promising carotenoid candidate for treatment of COVID-19 is astaxanthin due to its countless proprieties and antioxidant activities against several symptoms of viral infections, such as inflammation. In addition, astaxanthin is a multi-target agent that exhibits potential anti-inflammatory effects via several mechanisms of action and an acceptable safety profile when administrated at doses of 2 to $24 \mathrm{mg} / \mathrm{d}$ (Fakhri et al., 2020). Similarly, lycopene, crocin, and crocetin exhibit anti-viral roles, owing to their effects on several pathways implicated in asthmatic and airway inflammation.

However, carotenoids, which are natural compounds derived from the Plant kingdom, require more intensive research to better understand their potential independent roles in human disease prevention, particularly in the context of newly emerging diseases. Therefore, future research should isolate and characterize the pharmacology of each compound both in vitro and in vivo to define their activities and to determine the optimal doses of each compound, accounting for toxicity and possible side effects. However, before carotenoids can be utilized medically, their bioavailability, which varies depending on dietary factors and genetic variants (Desmarchelier and Borel, 2017), must be considered and thoroughly evaluated through extensive in vitro and in vivo studies.

\section{AUTHOR DISCLOSURE STATEMENT}

The authors declare no conflict of interest.

\section{REFERENCES}

Aanouz I, Belhassan A, El-Khatabi K, Lakhlifi T, El-Ldrissi M, Bouachrine M. Moroccan medicinal plants as inhibitors against SARS-CoV-2 main protease: computational investigations. J Biomol Struct Dyn. 2021. 39:2971-2979.

Ackermann M, Verleden SE, Kuehnel M, Haverich A, Welte T, Laenger F, et al. Pulmonary vascular endothelialitis, thrombosis, and angiogenesis in Covid-19. N Engl J Med. 2020. 383: 120-128.

Agarwal S, Rao AV. Tomato lycopene and its role in human health and chronic diseases. CMAJ. 2000. 163:739-744.

Akduman H, Tayman C, Çakir U, Çakir E, Dilli D, Türkmenoğlu
TT, et al. Astaxanthin prevents lung injury due to hyperoxia and inflammation. Comb Chem High Throughput Screen. 2021. 24:1243-1250.

Alharthy A, Faqihi F, Memish ZA, Karakitsos D. Lung injury in COVID-19-an emerging hypothesis. ACS Chem Neurosci. 2020. 11:2156-2158.

Alon R, Sportiello M, Kozlovski S, Kumar A, Reilly EC, Zarbock A, et al. Leukocyte trafficking to the lungs and beyond: lessons from influenza for COVID-19. Nat Rev Immunol. 2021. 21:4964.

Alqahtani JS, Oyelade T, Aldhahir AM, Alghamdi SM, Almehmadi $\mathrm{M}$, Alqahtani AS, et al. Prevalence, severity and mortality associated with COPD and smoking in patients with COVID-19: a rapid systematic review and meta-analysis. PLoS One. 2020. 15:e0233147. https://doi.org/10.1371/journal.pone.0233147

Ambati RR, Phang SM, Ravi S, Aswathanarayana RG. Astaxanthin: sources, extraction, stability, biological activities and its commercial applications - a review. Mar Drugs. 2014. 12:128152.

Anand AV, Balamuralikrishnan B, Kaviya M, Bharathi K, Parithathvi A, Arun M, et al. Medicinal plants, phytochemicals, and herbs to combat viral pathogens including SARS-CoV-2. Molecules. 2021. 26:1775. https://doi.org/10.3390/molecules 26061775

Aydin S, Palabiyik SS, Erkekoglu P, Sahin G, Başaran N, Giray BK. The carotenoid lycopene protects rats against DNA damage induced by ochratoxin A. Toxicon. 2013. 73:96-103.

Baeten JM, McClelland RS, Wener MH, Bankson DD, Lavreys L, Mandaliya K, et al. Relationship between markers of HIV-1 disease progression and serum $\beta$-carotene concentrations in Kenyan women. Int J STD AIDS. 2007. 18:202-206.

Bai SK, Lee SJ, Na HJ, Ha KS, Han JA, Lee H, et al. $\beta$-Carotene inhibits inflammatory gene expression in lipopolysaccharidestimulated macrophages by suppressing redox-based NF- $\kappa B$ activation. Exp Mol Med. 2005. 37:323-334.

Bendich A. $\beta$-Carotene and the immune response. Proc Nutr Soc. 1991. 50:263-274.

Bi J, Cui R, Li Z, Liu C, Zhang J. Astaxanthin alleviated acute lung injury by inhibiting oxidative/nitrative stress and the inflammatory response in mice. Biomed Pharmacother. 2017. 95:974982.

Böhm V, Lietz G, Olmedilla-Alonso B, Phelan D, Reboul E, Bánati $\mathrm{D}$, et al. From carotenoid intake to carotenoid blood and tissue concentrations - implications for dietary intake recommendations. Nutr Rev. 2021. 79:544-573.

Bukhari SI, Pattnaik B, Rayees S, Kaul S, Dhar MK. Safranal of Crocus sativus $\mathrm{L}$. inhibits inducible nitric oxide synthase and attenuates asthma in a mouse model of asthma. Phytother Res. 2015. 29:617-627.

Burri BJ, La Frano MR, Zhu C. Absorption, metabolism, and functions of $\beta$-cryptoxanthin. Nutr Rev. 2016. 74:69-82.

Burri BJ. Beta-cryptoxanthin as a source of vitamin A. J Sci Food Agric. 2015. 95:1786-1794.

Burrows TL, Williams R, Rollo M, Wood L, Garg ML, Jensen M, et al. Plasma carotenoid levels as biomarkers of dietary carotenoid consumption: a systematic review of the validation studies. J Nutr Intermed Metab. 2015. 2:15-64.

Cai X, Chen Y, Xie X, Yao D, Ding C, Chen M. Astaxanthin prevents against lipopolysaccharide-induced acute lung injury and sepsis via inhibiting activation of MAPK/NF- $\kappa$ B. Am J Transl Res. 2019. 11:1884-1894.

Campos KKD, Araújo GR, Martins TL, Bandeira ACB, Costa GP, Talvani A, et al. The antioxidant and anti-inflammatory properties of lycopene in mice lungs exposed to cigarette smoke. J Nutr Biochem. 2017. 48:9-20.

Catanzaro M, Fagiani F, Racchi M, Corsini E, Govoni S, Lanni C. Immune response in COVID-19: addressing a pharmacologi- 
cal challenge by targeting pathways triggered by SARS-CoV-2. Signal Transduct Target Ther. 2020. 5:84. https://doi.org/10. 1038/s41392-020-0191-1

Chen H, Wang J, Li R, Lv C, Xu P, Wang Y, et al. Astaxanthin attenuates pulmonary fibrosis through lncITPF and mitochondria-mediated signal pathways. J Cell Mol Med. 2020a. 24: 10245-10250.

Chen X, Chen Y, Chen Y, Wang X, He M. Protective effect of lutein on oxidative stress damage caused by acute PM2.5 exposure in rats. Ann Palliat Med. 2020b. 9:2028-2036.

Chen Z, Xiao J, Liu H, Yao K, Hou X, Cao Y, et al. Astaxanthin attenuates oxidative stress and immune impairment in D-galactose-induced aging in rats by activating the Nrf2/Keap1 pathway and suppressing the NF- $\mathrm{BB}$ pathway. Food Funct. 2020c. 11:8099-8111.

Cheng J, Eroglu A. The promising effects of astaxanthin on lung diseases. Adv Nutr. 2021. 12:850-864.

Cho KS, Shin M, Kim S, Lee SB. Recent advances in studies on the therapeutic potential of dietary carotenoids in neurodegenerative diseases. Oxid Med Cell Longev. 2018a. 2018:4120458. https://doi.org/10.1155/2018/4120458

Cho SO, Kim MH, Kim H. $\beta$-Carotene inhibits activation of NF$\kappa \mathrm{B}$, activator protein-1, and STAT3 and regulates abnormal expression of some adipokines in 3T3-L1 adipocytes. J Cancer Prev. 2018b. 23:37-43.

Coperchini F, Chiovato L, Croce L, Magri F, Rotondi M. The cytokine storm in COVID-19: an overview of the involvement of the chemokine/chemokine-receptor system. Cytokine Growth Factor Rev. 2020. 53:25-32.

Coronel J, Pinos I, Amengual J. $\beta$-Carotene in obesity research: technical considerations and current status of the field. Nutrients. 2019. 11:842. https://doi.org/10.3390/nu11040842

Costa AN, de Sá ÉRA, Bezerra RDS, Souza JL, Lima FDCA. Constituents of buriti oil (Mauritia flexuosa L.) like inhibitors of the SARS-coronavirus main peptidase: an investigation by docking and molecular dynamics. J Biomol Struct Dyn. 2021. 39: 4610-4617.

Cser MA, Majchrzak D, Rust P, Sziklai-László I, Kovács I, Bocskai E, et al. Serum carotenoid and retinol levels during childhood infections. Ann Nutr Metab. 2004. 48:156-162.

Cui B, Liu S, Wang Q, Lin X. Effect of $\beta$-carotene on immunity function and tumour growth in hepatocellular carcinoma rats. Molecules. 2012. 17:8595-8603.

D'Adamo CR, Miller RR, Shardell MD, Orwig DL, Hochberg MC, Ferrucci L, et al. Higher serum concentrations of dietary antioxidants are associated with lower levels of inflammatory biomarkers during the year after hip fracture. Clin Nutr. 2012. 31: 659-665.

Darvish Damavandi R, Mousavi SN, Shidfar F, Mohammadi V, Rajab A, Hosseini S, et al. Effects of daily consumption of cashews on oxidative stress and atherogenic indices in patients with type 2 diabetes: a randomized, controlled-feeding trial. Int J Endocrinol Metab. 2019. 17:e70744. https://doi.org/10. 5812/ijem.70744

Davinelli S, Melvang HM, Andersen LP, Scapagnini G, Nielsen ME. Astaxanthin from shrimp cephalothorax stimulates the immune response by enhancing IFN- $\gamma$, IL-10, and IL- 2 secretion in splenocytes of Helicobacter pylori-infected mice. Mar Drugs. 2019. 17:382. https://doi.org/10.3390/md17070382

Davinelli S, Nielsen ME, Scapagnini G. Astaxanthin in skin health, repair, and disease: a comprehensive review. Nutrients. 2018. 10:522. https://doi.org/10.3390/nu10040522

Desmarchelier C, Borel P. Overview of carotenoid bioavailability determinants: from dietary factors to host genetic variations. Trends Food Sci Technol. 2017. 69:270-280.

Di Filippo MM, Mathison BD, Park JS, Chew BP. Lutein and $\beta$ cryptoxanthin inhibit inflammatory mediators in human chon- drosarcoma cells induced with IL-1 1 . Open Nutr J. 2012. 6:4147.

Di Mascio P, Kaiser S, Sies H. Lycopene as the most efficient biological carotenoid singlet oxygen quencher. Arch Biochem Biophys. 1989. 274:532-538.

Ding J, Su J, Zhang L, Ma J. Crocetin activates Foxp3 through TIPE2 in asthma-associated Treg cells. Cell Physiol Biochem. 2015. 37:2425-2433.

Donà G, Andrisani A, Tibaldi E, Brunati AM, Sabbadin C, Armanini D, et al. Astaxanthin prevents human papillomavirus L1 protein binding in human sperm membranes. Mar Drugs. 2018. 16:427. https://doi.org/10.3390/md16110427

Dong E, Du H, Gardner L. An interactive web-based dashboard to track COVID-19 in real time. Lancet Infect Dis. 2020. 20:533534.

Du J, Chi Y, Song Z, Di Q, Mai Z, Shi J, et al. Crocin reduces Aspergillus fumigatus-induced airway inflammation and NF- $\mathrm{KB}$ signal activation. J Cell Biochem. 2018. 119:1746-1754.

Eisenhauer B, Natoli S, Liew G, Flood VM. Lutein and zeaxanthinfood sources, bioavailability and dietary variety in age-related macular degeneration protection. Nutrients. 2017. 9:120. https://doi.org/10.3390/nu9020120

Eze ED, Afodun AM, Kasolo J, Kasozi KI. Lycopene improves on basic hematological and immunological parameters in diabetes mellitus. BMC Res Notes. 2019. 12:805. https://doi.org/ 10.1186/s13104-019-4841-8

Fakhri S, Nouri Z, Moradi SZ, Farzaei MH. Astaxanthin, COVID19 and immune response: focus on oxidative stress, apoptosis and autophagy. Phytother Res. 2020. 34:2790-2792.

Fasogbon BM, Ademuyiwa OH, Bamidele OP, Wahab IE, OlaAdedoyin AT, Alakija O. Positive therapeutic role of selected foods and plant on ailments with a trend towards COVID-19: a review. Prev Nutr Food Sci. 2021. 26:1-11.

Fatima K, Mathew S, Suhail M, Ali A, Damanhouri G, Azhar E, et al. Docking studies of Pakistani HCV NS3 helicase: a possible antiviral drug target. PLoS One. 2014. 9:e106339. https://doi. org/10.1371/journal.pone.0106339

Fernandez IE, Eickelberg O. New cellular and molecular mechanisms of lung injury and fibrosis in idiopathic pulmonary fibrosis. Lancet. 2012. 380:680-688.

Fiedor J, Burda K. Potential role of carotenoids as antioxidants in human health and disease. Nutrients. 2014. 6:466-488.

Fryburg DA, Mark RJ, Griffith BP, Askenase PW, Patterson TF. The effect of supplemental beta-carotene on immunologic indices in patients with AIDS: a pilot study. Yale J Biol Med. 1995. 68:19-23.

Fuller B, Smith D, Howerton A, Kern D. Anti-inflammatory effects of CoQ10 and colorless carotenoids. J Cosmet Dermatol. 2006. 5:30-38.

Furman D, Campisi J, Verdin E, Carrera-Bastos P, Targ S, Franceschi C, et al. Chronic inflammation in the etiology of disease across the life span. Nat Med. 2019. 25:1822-1832.

Gallelli L, Zhang L, Wang T, Fu F. Severe acute lung injury related to COVID-19 infection: a review and the possible role for escin. J Clin Pharmacol. 2020. 60:815-825.

Garewal HS, Ampel NM, Watson RR, Prabhala RH, Dols CL. A preliminary trial of beta-carotene in subjects infected with the human immunodeficiency virus. J Nutr. 1992. 122:728-732.

Ghodratizadeh S, Kanbak G, Beyramzadeh M, Dikmen ZG, Memarzadeh S, Habibian R. Effect of carotenoid $\beta$-cryptoxanthin on cellular and humoral immune response in rabbit. Vet Res Commun. 2014. 38:59-62.

Goyal P, Choi JJ, Pinheiro LC, Schenck EJ, Chen R, Jabri A, et al. Clinical characteristics of covid-19 in New York city. N Engl J Med. 2020. 382:2372-2374.

Grievink L, de Waart FG, Schouten EG, Kok FJ. Serum carotenoids, $\alpha$-tocopherol, and lung function among Dutch elderly. 
Am J Respir Crit Care Med. 2000. 161:790-795.

Guénégou A, Leynaert B, Pin I, Le Moël G, Zureik M, Neukirch F. Serum carotenoids, vitamins $A$ and $E$, and 8 year lung function decline in a general population. Thorax. 2006. 61:320-326.

Harik-Khan RI, Muller DC, Wise RA. Serum vitamin levels and the risk of asthma in children. Am J Epidemiol. 2004. 159:351357.

Harrison EH. Mechanisms involved in the intestinal absorption of dietary vitamin A and provitamin A carotenoids. Biochim Biophys Acta. 2012. 1821:70-77.

Hashemzaei M, Mamoulakis C, Tsarouhas K, Georgiadis G, Lazopoulos G, Tsatsakis A, et al. Crocin: a fighter against inflammation and pain. Food Chem Toxicol. 2020. 143:111521. https://doi.org/10.1016/j.fct.2020.111521

Havas F, Krispin S, Meléndez-Martínez AJ, von Oppen-Bezalel L. Preliminary data on the safety of phytoene- and phytofluenerich products for human use including topical application. J Toxicol. 2018. 2018:5475784. https://doi.org/10.1155/2018 $/ 5475784$

Hazlewood LC, Wood LG, Hansbro PM, Foster PS. Dietary lycopene supplementation suppresses Th2 responses and lung eosinophilia in a mouse model of allergic asthma. J Nutr Biochem. 2011. 22:95-100.

Hegazy GE, Abu-Serie MM, Abo-Elela GM, Ghozlan H, Sabry SA, Soliman NA, et al. In vitro dual (anticancer and antiviral) activity of the carotenoids produced by haloalkaliphilic archaeon Natrialba sp. M6. Sci Rep. 2020. 10:5986. https://doi.org/10. 1038/s41598-020-62663-y

Herold T, Jurinovic V, Arnreich C, Lipworth BJ, Hellmuth JC, von Bergwelt-Baildon M, et al. Elevated levels of IL- 6 and CRP predict the need for mechanical ventilation in COVID-19. J Allergy Clin Immunol. 2020. 146:128-136.e4.

Holden JM, Eldridge AL, Beecher GR, Buzzard IM, Bhagwat S, Davis CS, et al. Carotenoid content of U.S. foods: an update of the database. J Food Compos Anal. 1999. 12:169-196.

Hua Y, Xu N, Ma T, Liu Y, Xu H, Lu Y. Anti-inflammatory effect of lycopene on experimental spinal cord ischemia injury via cyclooxygenase-2 suppression. Neuroimmunomodulation. 2019. 26:84-92.

Huang C, Wang Y, Li X, Ren L, Zhao J, Hu Y, et al. Clinical features of patients infected with 2019 novel coronavirus in Wuhan, China. The Lancet. 2020a. 395:497-506.

Huang Q, Wu X, Zheng X, Luo S, Xu S, Weng J. Targeting inflammation and cytokine storm in COVID-19. Pharmacol Res. 2020b. 159:105051. https://doi.org/10.1016/j.phrs.2020. 105051

Hwang YH, Hong SG, Mun SK, Kim SJ, Lee SJ, Kim JJ, et al. The protective effects of astaxanthin on the OVA-induced asthma mice model. Molecules. 2017. 22:2019. https://doi.org/10. 3390/molecules22112019

Iddir M, Brito A, Dingeo G, Fernandez Del Campo SS, Samouda $\mathrm{H}$, La Frano MR, et al. Strengthening the immune system and reducing inflammation and oxidative stress through diet and nutrition: considerations during the COVID-19 crisis. Nutrients. 2020. 12:1562. https://doi.org/10.3390/nu12061562

Jiao Y, Reuss L, Wang Y. $\beta$-Cryptoxanthin: chemistry, occurrence, and potential health benefits. Curr Pharmacol Rep. 2019. 5:2034.

Joo YE, Karrasch T, Mühlbauer M, Allard B, Narula A, Herfarth $\mathrm{HH}$, et al. Tomato lycopene extract prevents lipopolysaccharide-induced NF- $\kappa \mathrm{B}$ signaling but worsens dextran sulfate sodium-induced colitis in NF- $\mathrm{KB}^{\mathrm{EGFP}}$ mice. PLoS One. 2009. 4: e4562. https://doi.org/10.1371/journal.pone.0004562

Jun L, Root M. Association of carotenoid intake with pulmonary function. J Am Coll Nutr. 2020. In press. https://doi.org/10. 1080/07315724.2020.1815608

Kang H, Kim H. Astaxanthin and $\beta$-carotene in Helicobacter pylori- induced gastric inflammation: a mini-review on action mechanisms. J Cancer Prev. 2017. 22:57-61.

Karpiński TM, Adamczak A. Fucoxanthin - an antibacterial carotenoid. Antioxidants. 2019. 8:239. https://doi.org/10.3390/ antiox8080239

Khalil A, Tazeddinova D. The upshot of polyphenolic compounds on immunity amid COVID-19 pandemic and other emerging communicable diseases: an appraisal. Nat Prod Bioprospect. 2020. 10:411-429.

Kim GY, Kim JH, Ahn SC, Lee HJ, Moon DO, Lee CM, et al. Lycopene suppresses the lipopolysaccharide-induced phenotypic and functional maturation of murine dendritic cells through inhibition of mitogen-activated protein kinases and nuclear factor- $\kappa B$. Immunology. 2004. 113:203-211.

Kim HW, Chew BP, Wong TS, Park JS, Weng BB, Byrne KM, et al. Dietary lutein stimulates immune response in the canine. Vet Immunol Immunopathol. 2000a. 74:315-327.

Kim HW, Chew BP, Wong TS, Park JS, Weng BB, Byrne KM, et al. Modulation of humoral and cell-mediated immune responses by dietary lutein in cats. Vet Immunol Immunopathol. 2000b. 73:331-341.

Kim JH, Na HJ, Kim CK, Kim JY, Ha KS, Lee H, et al. The nonprovitamin A carotenoid, lutein, inhibits NF- $\kappa B$-dependent gene expression through redox-based regulation of the phosphatidylinositol 3-kinase/PTEN/Akt and NF-kB-inducing kinase pathways: role of $\mathrm{H}_{2} \mathrm{O}_{2}$ in NF- $\kappa \mathrm{B}$ activation. Free Radic Biol Med. 2008. 45:885-896.

Kim MB, Kang H, Li Y, Park YK, Lee JY. Fucoxanthin inhibits lipopolysaccharide-induced inflammation and oxidative stress by activating nuclear factor E2-related factor 2 via the phosphatidylinositol 3-kinase/AKT pathway in macrophages. Eur J Nutr. 2021. 60:3315-3324.

Kiokias S, Proestos C, Varzakas T. A review of the structure, biosynthesis, absorption of carotenoids-analysis and properties of their common natural extracts. Curr Res Nutr Food Sci. 2016. 4:25-37.

Kishimoto Y, Yoshida H, Kondo K. Potential anti-atherosclerotic properties of astaxanthin. Mar Drugs. 2016. 14:35. https:// doi.org/10.3390/md14020035

Kobori M, Ni Y, Takahashi Y, Watanabe N, Sugiura M, Ogawa K, et al. $\beta$-Cryptoxanthin alleviates diet-induced nonalcoholic steatohepatitis by suppressing inflammatory gene expression in mice. PLoS One. 2014. 9:e98294. https://doi.org/10.1371/ journal.pone.0098294

Korkmaz B, Lesner A, Marchand-Adam S, Moss C, Jenne DE. Lung protection by cathepsin $\mathrm{C}$ inhibition: a new hope for COVID-19 and ARDS?. J Med Chem. 2020. 63:13258-13265.

Krinsky NI, Johnson EJ. Carotenoid actions and their relation to health and disease. Mol Aspects Med. 2005. 26:459-516.

Krinsky NI, Landrum JT, Bone RA. Biologic mechanisms of the protective role of lutein and zeaxanthin in the eye. Annu Rev Nutr. 2003. 23:171-201.

Kubo H, Asai K, Kojima K, Sugitani A, Kyomoto Y, Okamoto A, et al. Astaxanthin suppresses cigarette smoke-induced emphysema through Nrf2 activation in mice. Mar Drugs. 2019. 17:673. https://doi.org/10.3390/md17120673

Landells LJ, Jensen MW, Orr LM, Spina D, O’Connor BJ, Page CP. The role of adenosine receptors in the action of theophylline on human peripheral blood mononuclear cells from healthy and asthmatic subjects. Br J Pharmacol. 2000. 129:1140-1144.

Lee CM, Chang JH, Moon DO, Choi YH, Choi IW, Park YM, et al. Lycopene suppresses ovalbumin-induced airway inflammation in a murine model of asthma. Biochem Biophys Res Commun. 2008. 374:248-252.

Leung JM, Niikura M, Yang CWT, Sin DD. COVID-19 and COPD. Eur Respir J. 2020. 56:2002108. https://doi.org/10.1183/ 13993003.02108-2020 
Li C, Ford ES, Zhao G, Balluz LS, Giles WH, Liu S. Serum $\alpha$-carotene concentrations and risk of death among US adults: the Third National Health and Nutrition Examination Survey Follow-up Study. Arch Intern Med. 2011. 171:507-515.

Li J, Xia Y, Liu T, Dai W, Wang F, Zheng Y, et al. Protective effects of astaxanthin on ConA-induced autoimmune hepatitis by the $\mathrm{JNK} / \mathrm{p}-\mathrm{JNK}$ pathway-mediated inhibition of autophagy and apoptosis. PLoS One. 2015. 10:e0120440. https://doi.org/10. 1371/journal.pone.0120440

Li R, Wu K, Li Y, Liang X, Tse WKF, Yang L, et al. Revealing the targets and mechanisms of vitamin $\mathrm{A}$ in the treatment of COVID-19. Aging. 2020. 12:15784-15796.

Li WW, Wang TY, Cao B, Liu B, Rong YM, Wang JJ, et al. Synergistic protection of matrine and lycopene against lipopolysaccharide-induced acute lung injury in mice. Mol Med Rep. 2019. 20:455-462.

Liebler DC, McClure TD. Antioxidant reactions of $\beta$-carotene: identification of carotenoid-radical adducts. Chem Res Toxicol. 1996. 9:8-11.

Lin HW, Chang TJ, Yang DJ, Chen YC, Wang M, Chang YY. Regulation of virus-induced inflammatory response by $\beta$-carotene in RAW264.7 cells. Food Chem. 2012. 134:2169-2175.

Lin KH, Lin KC, Lu WJ, Thomas PA, Jayakumar T, Sheu JR. Astaxanthin, a carotenoid, stimulates immune responses by enhancing IFN- $\gamma$ and IL-2 secretion in primary cultured lymphocytes in vitro and ex vivo. Int J Mol Sci. 2015. 17:44. https:// doi.org/10.3390/ijms17010044

Lin LJ, Wu CJ, Wang SD, Kao ST. Qi-Wei-Du-Qi-Wan and its major constituents exert an anti-asthmatic effect by inhibiting mast cell degranulation. J Ethnopharmacol. 2020. 254:112406. https://doi.org/10.1016/j.jep.2019.112406

Liu C, Bronson RT, Russell RM, Wang XD. $\beta$-Cryptoxanthin supplementation prevents cigarette smoke-induced lung inflammation, oxidative damage, and squamous metaplasia in ferrets. Cancer Prev Res. 2011. 4:1255-1266.

Liu CC, Huang CC, Lin WT, Hsieh CC, Huang SY, Lin SJ, et al. Lycopene supplementation attenuated xanthine oxidase and myeloperoxidase activities in skeletal muscle tissues of rats after exhaustive exercise. Br J Nutr. 2005. 94:595-601.

Liu S, Yang D, Yu L, Aluo Z, Zhang Z, Qi Y, et al. Effects of lycopene on skeletal muscle-fiber type and high-fat diet-induced oxidative stress. J Nutr Biochem. 2021. 87:108523. https:// doi.org/10.1016/j.jnutbio.2020.108523

Liu YZ, Yang CM, Chen JY, Liao JW, Hu ML. Alpha-carotene inhibits metastasis in Lewis lung carcinoma in vitro, and suppresses lung metastasis and tumor growth in combination with taxol in tumor xenografted C57BL/6 mice. J Nutr Biochem. 2015. 26:607-615.

Luo C, Wu XG. Lycopene enhances antioxidant enzyme activities and immunity function in N-methyl-N'-nitro-N-nitrosoguanidine-enduced gastric cancer rats. Int J Mol Sci. 2011. 12:33403351.

Luo L, Fang K, Dan X, Gu M. Crocin ameliorates hepatic steatosis through activation of AMPK signaling in $\mathrm{db} / \mathrm{db}$ mice. Lipids Health Dis. 2019. 18:11. https://doi.org/10.1186/s12944018-0955-6

Ma SY, Park WS, Lee DS, Choi G, Yim MJ, Lee JM, et al. Fucoxanthin inhibits profibrotic protein expression in vitro and attenuates bleomycin-induced lung fibrosis in vivo. Eur J Pharmacol. 2017. 811:199-207.

Mangels AR, Holden JM, Beecher GR, Forman MR, Lanza E. Carotenoid content of fruits and vegetables: an evaluation of analytic data. J Am Diet Assoc. 1993. 93:284-296.

Maoka T. Carotenoids as natural functional pigments. J Nat Med. 2020. 74:1-16.

Mapelli-Brahm P, Corte-Real J, Meléndez-Martínez AJ, Bohn T. Bioaccessibility of phytoene and phytofluene is superior to oth- er carotenoids from selected fruit and vegetable juices. Food Chem. 2017. 229:304-311.

Meléndez-Martínez AJ, Mapelli-Brahm P, Benítez-González A, Stinco CM. A comprehensive review on the colorless carotenoids phytoene and phytofluene. Arch Biochem Biophys. 2015. 572:188-200.

Meléndez-Martínez AJ, Mapelli-Brahm P, Hornero-Méndez D, Vicario IM. Structures, nomenclature and general chemistry of carotenoids and their esters. In: Mercadante AZ, editor. Food Chemistry, Function and Analysis: Carotenoid Esters in Foods - Physical, Chemical and Biological Properties. Royal Society of Chemistry, London, UK. 2019. p 1-50.

Melo van Lent D, Leermakers ETM, Darweesh SKL, Moreira EM, Tielemans MJ, Muka T, et al. The effects of lutein on respiratory health across the life course: a systematic review. Clin Nutr ESPEN. 2016. 13:e1-e7.

Meza-Menchaca T, Lizano-Soberón M, Trigos A, Zepeda RC, Medina ME, Galindo-Murillo R. Elucidating molecular interactions of ten natural compounds targeting E6 HPV high risk oncoproteins using microsecond molecular dynamics simulations. Med Chem. 2021. 17:587-600.

Milani A, Basirnejad M, Shahbazi S, Bolhassani A. Carotenoids: biochemistry, pharmacology and treatment. Br J Pharmacol. 2017. 174:1290-1324.

Mohamadpour AH, Ayati Z, Parizadeh MR, Rajbai O, Hosseinzadeh $\mathrm{H}$. Safety evaluation of crocin (a constituent of saffron) tablets in healthy volunteers. Iran J Basic Med Sci. 2013. 16:3946.

Mokhtari-Zaer A, Khazdair MR, Boskabady MH. Smooth muscle relaxant activity of Crocus sativus (saffron) and its constituents: possible mechanisms. Avicenna J Phytomed. 2015. 5:365-375.

Monteiro JP, Freimanis-Hance L, Faria LB, Mussi-Pinhata MM, Korelitz J, Vannucchi H, et al. Both human immunodeficiency virus-infected and human immunodeficiency virus-exposed, uninfected children living in Brazil, Argentina, and Mexico have similar rates of low concentrations of retinol, beta-carotene, and vitamin E. Nutr Res. 2009. 29:716-722.

Morvaridzadeh M, Fazelian S, Agah S, Khazdouz M, Rahimlou M, Agh F, et al. Effect of ginger (Zingiber officinale) on inflammatory markers: a systematic review and meta-analysis of randomized controlled trials. Cytokine. 2020. 135:155224. https://doi. org/10.1016/j.cyto.2020.155224

Murakoshi M, Nishino H, Satomi Y, Takayasu J, Hasegawa T, Tokuda $\mathrm{H}$, et al. Potent preventive action of $\alpha$-carotene against carcinogenesis: spontaneous liver carcinogenesis and promoting stage of lung and skin carcinogenesis in mice are suppressed more effectively by $\alpha$-carotene than by $\beta$-carotene. Cancer Res. 1992. 52:6583-6587.

Murakoshi M, Takayasu J, Kimura O, Kohmura E, Nishino H, Iwashima A, et al. Inhibitory effects of $\alpha$-carotene on proliferation of the human neuroblastoma cell line GOTO. J Natl Cancer Inst. 1989. 81:1649-1652.

Mustra Rakic J, Liu C, Veeramachaneni S, Wu D, Paul L, Chen CO, et al. Lycopene inhibits smoke-induced chronic obstructive pulmonary disease and lung carcinogenesis by modulating reverse cholesterol transport in ferrets. Cancer Prev Res. 2019. 12:421-432.

Mustra Rakic J, Wang XD. Role of lycopene in smoke-promoted chronic obstructive pulmonary disease and lung carcinogenesis. Arch Biochem Biophys. 2020. 689:108439. https://doi. org/10.1016/j.abb.2020.108439

Nagata C, Shimizu H, Yoshikawa H, Noda K, Nozawa S, Yajima A, et al. Serum carotenoids and vitamins and risk of cervical dysplasia from a case-control study in Japan. Br J Cancer. 1999. 81:1234-1237.

Neyestani TR, Shariatzadeh N, Gharavi A, Kalayi A, Khalaji N. Physiological dose of lycopene suppressed oxidative stress and 
enhanced serum levels of immunoglobulin $m$ in patients with type 2 diabetes mellitus: a possible role in the prevention of long-term complications. J Endocrinol Invest. 2007. 30:833838.

Ni Y, Nagashimada M, Zhan L, Nagata N, Kobori M, Sugiura M, et al. Prevention and reversal of lipotoxicity-induced hepatic insulin resistance and steatohepatitis in mice by an antioxidant carotenoid, $\beta$-cryptoxanthin. Endocrinology. 2015. 156: 987-999.

Nian L, Weidong Z, Shujuan L, Jun C, Minlian P, Zhiguang L. Astaxanthin suppresses cigarette smoke and lipopolysaccharideinduced airway inflammation through induction of heme oxygenase-1. Cell Mol Biol. 2019. 65:94-99.

Nuss ET, Valentine AR, Zhang Z, Lai HJ, Tanumihardjo SA. Serum carotenoid interactions in premenopausal women reveal $\alpha$-carotene is negatively impacted by body fat. Exp Biol Med. 2017. 242:1262-1270.

Ochs-Balcom HM, Grant BJ, Muti P, Sempos CT, Freudenheim JL, Browne RW, et al. Antioxidants, oxidative stress, and pulmonary function in individuals diagnosed with asthma or COPD. Eur J Clin Nutr. 2006. 60:991-999.

Oh J, Kim JH, Park JG, Yi YS, Park KW, Rho HS, et al. Radical scavenging activity-based and AP-1-targeted anti-inflammatory effects of lutein in macrophage-like and skin keratinocytic cells. Mediators Inflamm. 2013. 2013:787042. https://doi. org/10.1155/2013/787042

Pang B, Wang C, Weng X, Tang X, Zhang H, Niu S, et al. Beta-carotene protects rats against bronchitis induced by cigarette smoking. Chin Med J. 2003. 116:514-516.

Pang R, Tao JY, Zhang SL, Zhao L, Yue X, Wang YF, et al. In vitro antiviral activity of lutein against hepatitis $B$ virus. Phytother Res. 2010. 24:1627-1630.

Park JS, Chyun JH, Kim YK, Line LL, Chew BP. Astaxanthin decreased oxidative stress and inflammation and enhanced immune response in humans. Nutr Metab. 2010. 7:18. https:// doi.org/10.1186/1743-7075-7-18

Peng J, Yuan JP, Wu CF, Wang JH. Fucoxanthin, a marine carotenoid present in brown seaweeds and diatoms: metabolism and bioactivities relevant to human health. Mar Drugs. 2011. 9:1806-1828.

Perico L, Benigni A, Casiraghi F, Ng LFP, Renia L, Remuzzi G. Immunity, endothelial injury and complement-induced coagulopathy in COVID-19. Nat Rev Nephrol. 2021. 17:46-64.

Promphet P, Bunarsa S, Sutheerawattananonda M, Kunthalert D. Immune enhancement activities of silk lutein extract from Bombyx mori cocoons. Biol Res. 2014. 47:15. https://doi.org/ 10.1186/0717-6287-47-15

Rao AV, Rao LG. Carotenoids and human health. Pharmacol Res. 2007. 55:207-216.

Riccioni G, Bucciarelli T, Mancini B, Di Ilio C, Della Vecchia R, D'Orazio N. Plasma lycopene and antioxidant vitamins in asthma: the PLAVA study. J Asthma. 2007. 44:429-432.

Robertson RC, Guihéneuf F, Bahar B, Schmid M, Stengel DB, Fitzgerald GF, et al. The anti-inflammatory effect of algae-derived lipid extracts on lipopolysaccharide (LPS)-stimulated human THP-1 macrophages. Mar Drugs. 2015. 13:5402-5424.

Rubin LP, Chan GM, Barrett-Reis BM, Fulton AB, Hansen RM, Ashmeade TL, et al. Effect of carotenoid supplementation on plasma carotenoids, inflammation and visual development in preterm infants. J Perinatol. 2012. 32:418-424.

Ruiz-Sola MÁ, Rodríguez-Concepción M. Carotenoid biosynthesis in Arabidopsis: a colorful pathway. Arabidopsis Book. 2012. 10:e0158. https://doi.org/10.1199/tab.0158

Saedisomeolia A, Wood LG, Garg ML, Gibson PG, Wark PA. Lycopene enrichment of cultured airway epithelial cells decreases the inflammation induced by rhinovirus infection and lipopolysaccharide. J Nutr Biochem. 2009. 20:577-585.
Sahin K, Orhan C, Akdemir F, Tuzcu M, Sahin N, Yllmaz I, et al. $\beta$-Cryptoxanthin ameliorates metabolic risk factors by regulating NF- $\kappa \mathrm{B}$ and Nrf2 pathways in insulin resistance induced by high-fat diet in rodents. Food Chem Toxicol. 2017. 107:270279.

Sakai S, Sugawara T, Matsubara K, Hirata T. Inhibitory effect of carotenoids on the degranulation of mast cells via suppression of antigen-induced aggregation of high affinity IgE receptors. J Biol Chem. 2009. 284:28172-28179.

Santoyo S, Jaime L, Plaza M, Herrero M, Rodriguez-Meizoso I, Ibañez E, et al. Antiviral compounds obtained from microalgae commonly used as carotenoid sources. J Appl Phycol. 2012. 24: 731-741.

Sayahi M, Shirali S. The antidiabetic and antioxidant effects of carotenoids: a review. J Pharm Res Health Care. 2017. 9:186191.

Schock BC, Young IS, Brown V, Fitch PS, Shields MD, Ennis M. Antioxidants and oxidative stress in BAL fluid of atopic asthmatic children. Pediatr Res. 2003. 53:375-381.

Semba RD, Chang SS, Sun K, Talegawkar S, Ferrucci L, Fried LP. Serum carotenoids and pulmonary function in older community-dwelling women. J Nutr Health Aging. 2012. 16:291-296.

Shaish A, Harari A, Kamari Y, Soudant E, Harats D, Ben-Amotz A. A carotenoid algal preparation containing phytoene and phytofluene inhibited LDL oxidation in vitro. Plant Foods Hum Nutr. 2008. 63:83-86.

Soleymani S, Zabihollahi R, Shahbazi S, Bolhassani A. Antiviral effects of saffron and its major ingredients. Curr Drug Deliv. 2018. 15:698-704.

Song JY, Lee CM, Lee MK. Lutein modulates Th2 immune response in ovalbumin-induced airway inflammation. J Life Sci. 2012. 22:298-305.

Song X, Wang B, Lin S, Jing L, Mao C, Xu P, et al. Astaxanthin inhibits apoptosis in alveolar epithelial cells type II in vivo and in vitro through the ROS-dependent mitochondrial signalling pathway. J Cell Mol Med. 2014. 18:2198-2212.

Sreekanth GP, Chuncharunee A, Yenchitsomanus PT, Limjindaporn T. Crocetin improves dengue virus-induced liver injury. Viruses. 2020. 12:825. https://doi.org/10.3390/v12080825

Stahl W, Sies H. Antioxidant activity of carotenoids. Mol Aspects Med. 2003. 24:345-351.

Story EN, Kopec RE, Schwartz SJ, Harris GK. An update on the health effects of tomato lycopene. Annu Rev Food Sci Technol. 2010. 1:189-210.

Su J, Guo K, Huang M, Liu Y, Zhang J, Sun L, et al. Fucoxanthin, a marine xanthophyll isolated from Conticribra weissflogii ND-8: preventive anti-inflammatory effect in a mouse model of sepsis. Front Pharmacol. 2019. 10:906. https://doi.org/10.3389/ fphar.2019.00906

Sugiura M. $\beta$-Cryptoxanthin and the risk for lifestyle-related disease: findings from recent nutritional epidemiologic studies. Yakugaku Zasshi. 2015. 135:67-76.

Sukhinin VP, Zarubaev VV, Platonov VG, Avtushenko SS. Effect of liposomal beta-carotene on experimentally lethal influenza infection. Vopr Virusol. 1999. 44:163-167.

Talukdar J, Bhadra B, Dattaroy T, Nagle V, Dasgupta S. Potential of natural astaxanthin in alleviating the risk of cytokine storm in COVID-19. Biomed Pharmacother. 2020. 132:110886. https://doi.org/10.1016/j.biopha.2020.110886

Tanumihardjo SA. Carotenoids: health effects. In: Caballero B, editor. Encyclopedia of Human Nutrition. 3rd ed. Academic Press, Oxford, UK. 2013. p 292-297.

Tay MZ, Poh CM, Rénia L, MacAry PA, Ng LFP. The trinity of COVID-19: immunity, inflammation and intervention. Nat Rev Immunol. 2020. 20:363-374.

Terao R, Murata A, Sugamoto K, Watanabe T, Nagahama K, Nakahara K, et al. Immunostimulatory effect of kumquat (For- 
tunella crassifolia) and its constituents, $\beta$-cryptoxanthin and R-limonene. Food Funct. 2019. 10:38-48.

Tian W, Zhang N, Jin R, Feng Y, Wang S, Gao S, et al. Immune suppression in the early stage of COVID-19 disease. Nat Commun. 2020. 11:5859. https://doi.org/10.1038/s41467-02019706-9

Tsushima M, Maoka T, Katsuyama M, Kozuka M, Matsuno T, Tokuda H, et al. Inhibitory effect of natural carotenoids on Epstein-Barr virus activation activity of a tumor promoter in Raji cells. A screening study for anti-tumor promoters. Biol Pharm Bull. 1995. 18:227-233.

van der Horst-Graat JM, Kok FJ, Schouten EG. Plasma carotenoid concentrations in relation to acute respiratory infections in elderly people. Br J Nutr. 2004. 92:113-118.

Wang J, Kuai J, Luo Z, Wang W, Wang L, Ke C, et al. Crocin attenuates lipopolysacchride-induced acute lung injury in mice. Int J Clin Exp Pathol. 2015a. 8:4844-4850.

Wang J, Suo Y, Zhang J, Zou Q, Tan X, Yuan T, et al. Lycopene supplementation attenuates western diet-induced body weight gain through increasing the expressions of thermogenic/mitochondrial functional genes and improving insulin resistance in the adipose tissue of obese mice. J Nutr Biochem. 2019a. 69: 63-72.

Wang J, Wang Z, Li B, Qiang Y, Yuan T, Tan X, et al. Lycopene attenuates western-diet-induced cognitive deficits via improving glycolipid metabolism dysfunction and inflammatory responses in gut-liver-brain axis. Int J Obes. 2019b. 43:1735-1746.

Wang M, Zhang J, Song X, Liu W, Zhang L, Wang X, et al. Astaxanthin ameliorates lung fibrosis in vivo and in vitro by preventing transdifferentiation, inhibiting proliferation, and promoting apoptosis of activated cells. Food Chem Toxicol. 2013. 56:450-458.

Wang Y, Cui R, Xiao Y, Fang J, Xu Q. Effect of carotene and lycopene on the risk of prostate cancer: a systematic review and dose-response meta-analysis of observational studies. PLoS One. 2015b. 10:e0137427. https://doi.org/10.1371/journal. pone. 0137427

Ware LB. Physiological and biological heterogeneity in COVID19-associated acute respiratory distress syndrome. Lancet Respir Med. 2020. 8:1163-1165.

Wawrzyniak A, Hamułka J, Friberg E, Wolk A. Dietary, anthropometric, and lifestyle correlates of serum carotenoids in postmenopausal women. Eur J Nutr. 2013. 52:1919-1926.

Wood LG, Garg ML, Blake RJ, Garcia-Caraballo S, Gibson PG. Airway and circulating levels of carotenoids in asthma and healthy controls. J Am Coll Nutr. 2005. 24:448-455.

Wood LG, Garg ML, Powell H, Gibson PG. Lycopene-rich treatments modify noneosinophilic airway inflammation in asthma: proof of concept. Free Radic Res. 2008. 42:94-102.

Woodside JV, McGrath AJ, Lyner N, McKinley MC. Carotenoids and health in older people. Maturitas. 2015. 80:63-68.

Xia QD, Xun Y, Lu JL, Lu YC, Yang YY, Zhou P, et al. Network pharmacology and molecular docking analyses on Lianhua Qingwen capsule indicate Akt1 is a potential target to treat and prevent COVID-19. Cell Prolif. 2020. 53:e12949. https://doi. org/10-1111/cpr.12949

Xie Y, He Q, Chen H, Lin Z, Xu Y, Yang C. Crocin ameliorates chronic obstructive pulmonary disease-induced depression via PI3K/Akt mediated suppression of inflammation. Eur J Pharmacol. 2019. 862:172640. https://doi.org/10.1016/j.ejphar. 2019.172640

Xiong Y, Wang J, Yu H, Zhang X, Miao C. Anti-asthma potential of crocin and its effect on MAPK signaling pathway in a murine model of allergic airway disease. Immunopharmacol Immunotoxicol. 2015. 37:236-243.
Xu G, Qi F, Li H, Yang Q, Wang H, Wang X, et al. The differential immune responses to COVID-19 in peripheral and lung revealed by single-cell RNA sequencing. Cell Discov. 2020. 6:73. https://doi.org/10.1038/s41421-020-00225-2

Xu W, Wang M, Cui G, Li L, Jiao D, Yao B, et al. Astaxanthin protects OTA-induced lung injury in mice through the Nrf2/NF$\kappa B$ pathway. Toxins. 2019. 11:540. https://doi.org/10.3390/ toxins11090540

Xu XR, Zou ZY, Xiao X, Huang YM, Wang X, Lin XM. Effects of lutein supplement on serum inflammatory cytokines, ApoE and lipid profiles in early atherosclerosis population. J Atheroscler Thromb. 2013. 20:170-177.

Yang R, Yang L, Shen X, Cheng W, Zhao B, Ali KH, et al. Suppression of NF- $\kappa B$ pathway by crocetin contributes to attenuation of lipopolysaccharide-induced acute lung injury in mice. Eur J Pharmacol. 2012. 674:391-396.

Yang X, Guo G, Dang M, Yan L, Kang X, Jia K, et al. Assessment of the therapeutic effects of fucoxanthin by attenuating inflammation in ovalbumin-induced asthma in an experimental animal model. J Environ Pathol Toxicol Oncol. 2019. 38:229-238.

Yarmohammadi A, Yarmohammadi M, Fakhri S, Khan H. Targeting pivotal inflammatory pathways in COVID-19: a mechanistic review. Eur J Pharmacol. 2021. 890:173620. https:// doi.org/10.1016/j.ejphar.2020.173620

Yosri H, Elkashef WF, Said E, Gameil NM. Crocin modulates IL-4 /IL-13 signaling and ameliorates experimentally induced allergic airway asthma in a murine model. Int Immunopharmacol. 2017. 50:305-312.

Yucel Y, Tabur S, Gozeneli O, Kocarslan S, Seker A, Buyukaslan H, et al. The effects of lycopene on intestinal injury due to methotrexate in rats. Redox Rep. 2016. 21:113-118.

Zeinali M, Zirak MR, Rezaee SA, Karimi G, Hosseinzadeh H. Immunoregulatory and anti-inflammatory properties of Crocus sativus (saffron) and its main active constituents: a review. Iran J Basic Med Sci. 2019. 22:334-344.

Zhang D, Qi BY, Zhu WW, Huang X, Wang XZ. Crocin alleviates lipopolysaccharide-induced acute respiratory distress syndrome by protecting against glycocalyx damage and suppressing inflammatory signaling pathways. Inflamm Res. 2020a. 69: 267-278.

Zhang F, Fu Y, Zhou X, Pan W, Shi Y, Wang M, et al. Depressionlike behaviors and heme oxygenase- 1 are regulated by lycopene in lipopolysaccharide-induced neuroinflammation. J Neuroimmunol. 2016. 298:1-8.

Zhang H, Tang Y, Zhang Y, Zhang S, Qu J, Wang X, et al. Fucoxanthin: a promising medicinal and nutritional ingredient. 2015a. 2015:723515. https://doi.org/10.1155/2015/723515

Zhang J, Xu P, Wang Y, Wang M, Li H, Lin S, et al. Astaxanthin prevents pulmonary fibrosis by promoting myofibroblast apoptosis dependent on Drp1-mediated mitochondrial fission. J Cell Mol Med. 2015b. 19:2215-2231.

Zhang L, Cao W, Gao Y, Yang R, Zhang X, Xua J, et al. Astaxanthin (ATX) enhances the intestinal mucosal functions in immunodeficient mice. Food Funct. 2020b. 11:3371-3381.

Zhao B, Wu J, Li J, Bai Y, Luo Y, Ji B, et al. Lycopene alleviates DSS-induced colitis and behavioral disorders via mediating microbes-gut-brain axis balance. J Agric Food Chem. 2020. 68: 3963-3975.

Zhao LG, Zhang QL, Zheng JL, Li HL, Zhang W, Tang WG, et al. Dietary, circulating beta-carotene and risk of all-cause mortality: a meta-analysis from prospective studies. Sci Rep. 2016. 6:26983. https://doi.org/10.1038/srep26983

Zhong J, Tang J, Ye C, Dong L. The immunology of COVID-19: is immune modulation an option for treatment?. The Lancet. 2020. 2:E428-E436. 